\title{
Metal-Organic Framework-Based Solid Acid Materials for Biomass Upgrade
}

\author{
Yutian Qin ${ }^{1} \cdot$ Jun Guo ${ }^{2}$ Meiting Zhao ${ }^{1}$
}

Received: 10 May 2021 / Revised: 18 May 2021 / Accepted: 27 May 2021 / Published online: 21 June 2021

(c) The Author(s) 2021

\begin{abstract}
Biomass is a green and producible source of energy and chemicals. Hence, developing high-efficiency catalysts for biomass utilization and transformation is urgently demanded. Metal-organic framework (MOF)-based solid acid materials have been considered as promising catalysts in biomass transformation. In this review, we first introduce the genre of Lewis acid and Brønsted acid sites commonly generated in MOFs or MOF-based composites. Then, the methods for the generation and adjustment of corresponding acid sites are overviewed. Next, the catalytic applications of MOF-based solid acid materials in various biomass transformation reactions are summarized and discussed. Furthermore, based on our personal insights, the challenges and outlook on the future development of MOF-based solid acid catalysts are provided. We hope that this review will provide an instructive roadmap for future research on MOFs and MOF-based composites for biomass transformation.
\end{abstract}

Keywords Metal-organic framework $\cdot$ Solid acid $\cdot$ Catalysis $\cdot$ Biomass $\cdot$ Glucose

\section{Introduction}

Since the Industrial Revolution, consumption by humans of fossil fuels, e.g., coal and petroleum, has increased rapidly. However, due to their nonrenewable nature as well as the massive emission of greenhouse gasses (e.g., $\mathrm{CO}_{2}, \mathrm{CH}_{4}$, and $\mathrm{NO}_{x}$ ) and other atmospheric pollutants (e.g., $\mathrm{SO}_{2}, \mathrm{CO}$, and inhalable particles) after combustion, exploitation and utilization of novel sustainable and green alternatives are urgently demanded [1-3]. Biomass, including cellulose, starch, monosaccharides, and terpenoids, is reproducible in organisms via photosynthesis and thus recognized as a carbon-neutral alternative. In the past two decades, the utilization and transformation of biomass to value-added fine chemicals and fuels have drawn global attention in both science and industry $[1,4]$.

Jun Guo

junguo@tiangong.edu.cn

Meiting Zhao

mtzhao@tju.edu.cn

1 Tianjin Key Laboratory of Molecular Optoelectronic Sciences, Institute of Molecular Aggregation Science, Tianjin University, Tianjin 300072, China

2 School of Chemistry, Tiangong University, Tianjin 300387, China
The transformation of biomass is associated with a series of chemical processes, of which the acid catalyst has been proven to be workable in hydrolysis, dehydration, reduction, and isomerization [5-7]. For instance, 5-hydroxymethylfurfural (5-HMF), a key product in saccharide upgrade, can be obtained from cellulose via three sequential sub-reactions, i.e., Brønsted acid-catalyzed cellulose hydrolysis, Lewis acid-catalyzed glucose isomerization, and Brønsted acidcatalyzed fructose dehydration. Moreover, 5-HMF can be further converted to other high value-added products, e.g., levulinic acid (via a Brønsted acid-catalyzed hydration process). Preferably, a catalyst containing both Brønsted and Lewis acidic sites is expected to convert cellulose to 5-HMF or even levulinic acid in a one-pot synthesis [8]. In industry, solid acid catalysts are more desired in biomass upgrade processes given their convenient product separation and catalyst recyclability $[9,10]$. Despite a few successes made by conventional solid catalysts, including zeolites, metal oxides, and acidic resins, their further advancing in biomass upgrade has been subjected to bottlenecks of relatively low surface area, ambiguous locations of active sites, and limited structural diversity [11].

Metal-organic frameworks (MOFs) are an emerging class of porous materials consisting of metal ions (or clusters) and organic polydentate ligands. Compared with other heterogeneous catalysts (e.g., porous silica, zeolites, 
metal oxides, carbon materials, and resins), MOFs typically have larger surface areas. In addition, in contrast to these conventional solid materials, MOFs possess tunable pore structures. Moreover, the inorganic-organic hybrid nature endows MOFs with facile modification strategies $[12,13]$. In terms of using MOF materials in heterogeneous catalysis, the larger surface area allows accommodating more active species per unit weight [14]; the appropriate pore dimension enables good molecule sieving function toward both substrates and catalytic products [15-17]; the versatile modification can further incorporate desired active moieties into MOF materials for performance improvement $[18,19]$. Therefore, MOFs or MOF-based composites are considered feasible candidates for heterogeneous catalysis, particularly acting as novel solid acid catalysts for biomass upgrade [20-23]. In this review, the design and preparation of MOF-based solid acids will be introduced first, and their catalytic application in biomass utilization will be summarized hereinafter. Also, an outlook based on our personal insights is provided for further advancing this field.

\section{Catalytic Sites of MOF-Based Solid Acid Catalysts}

In general, three types of acid sites in MOFs that can be utilized for catalytic conversion of biomass: (1) metal nodes, whose coordinatively unsaturated metal sites and weakly coordinated moieties (e.g., hydroxyl, water) could function as Lewis acid and Brønsted acid sites, respectively [24]; (2) acidic functional groups grafted on organic linkers [25]; (3) acidic guest species (e.g., polyoxometalate (POM) and metal oxide) accommodated inside the MOF materials [9].

\section{Metal Nodes as Acid Sites}

As the structural node of MOF materials, the metal ion or cluster, in some cases, is terminated by weakly coordinated moieties (e.g., water, $N, N$-dimethylformamide (DMF) or other solvents), which are readily removed via thermal activation. The resultant coordinatively unsaturated metal sites can exhibit Lewis acid activity [26]. On the other hand, the species bonded to metal atoms (e.g., the hydroxy bridge in metal clusters) can exhibit certain Brønsted acidity via dissociation of corresponding protons [27]. In the following content, the acidic nature of some typical MOF materials, e.g., Cu-BTC [28], MIL-100/101 [29], MOF-74 [30], UiO-66/67 [31], NU-1000 [32], and MOF-808 [33], will be described in detail.

$\mathrm{Cu}$-BTC (or $\mathrm{Cu}_{3}$ (BTC) $)_{2}$, HKUST-1) is composed of a trimesate (BTC) linker and binuclear $\mathrm{Cu}_{2}(\mathrm{COO})_{4}\left(\mathrm{H}_{2} \mathrm{O}\right)_{2}$ node, with the copper atom adopting a 6-coordinated model and forming an octahedron: four equator vertices are occupied with oxygen atoms from four separate trimesate linkers, one longitudinal position is occupied by the neighboring copper atom, and another one is terminated by a weakly coordinated water molecule. By thermal activation (e.g., at $\left.100{ }^{\circ} \mathrm{C}\right)$, the $\mathrm{Cu}_{2}(\mathrm{COO})_{4}\left(\mathrm{H}_{2} \mathrm{O}\right)_{2}$ node can be easily dehydrated and form the coordinatively unsaturated $\mathrm{Cu}_{2}(\mathrm{COO})_{4}$ site with Lewis acidity (Fig. 1a) [26, 34]. MIL-100/101 (i.e., $\mathrm{M}_{3} \mathrm{O}\left(\mathrm{H}_{2} \mathrm{O}\right)_{2} \mathrm{X}(\mathrm{BTC})_{2} / \mathrm{M}_{3} \mathrm{O}\left(\mathrm{H}_{2} \mathrm{O}\right)_{2} \mathrm{X}(\mathrm{BDC})_{3}$; $\mathrm{BDC}=$ terephthalate) consists of $\mathrm{M}_{3}\left(\mu_{3}-\mathrm{O}\right)(\mathrm{COO})_{6}\left(\mathrm{H}_{2} \mathrm{O}\right)_{2} \mathrm{X}$ clusters $\left(\mathrm{M}=\mathrm{Cr}^{3+}, \mathrm{Fe}^{3+} ; \mathrm{X}=\mathrm{OH}^{-}, \mathrm{F}^{-}\right)$and trimesate/terephthalate linkers. Among each 6-coordinated metal atom, one coordination site is occupied by $\mu_{3}-\mathrm{O}$, four are connected by carboxylate linkers, and the remaining one is taken by water or anion from the solvent/additive for MOF synthesis [35, 36]. Owing to the strong charge polarization of $\mathrm{M}^{3+}$, the $\mathrm{O}-\mathrm{H}$ bond in the coordinated water molecule was activated compared with that in free water, leading to certain Brønsted acidity. In addition, the liable water molecule could depart under thermal treatment and vacuum to generate coordinatively unsaturated metal sites with Lewis acidity (Fig. 1b) [26, 29]. MOF-74, also known as CPO-27, is a framework constructed with 6-coordinated $\mathrm{M}^{2+}$ ions $(\mathrm{M}=\mathrm{Mg}, \mathrm{Mn}, \mathrm{Fe}$, $\mathrm{Co}, \mathrm{Ni}, \mathrm{Cu}, \mathrm{Zn}$ ) and 2,5-dihydroxyterephthalate (DHTP) linkers [37]. Each $\mathrm{M}^{2+}$ ion is bound with three carboxyloxygen from three separate DHTP linkers and two aryloxyoxygen from two DHTP linkers. The sixth coordinative site, typically occupied by a solvent molecule, e.g., DMF or $\mathrm{H}_{2} \mathrm{O}$,

(a)

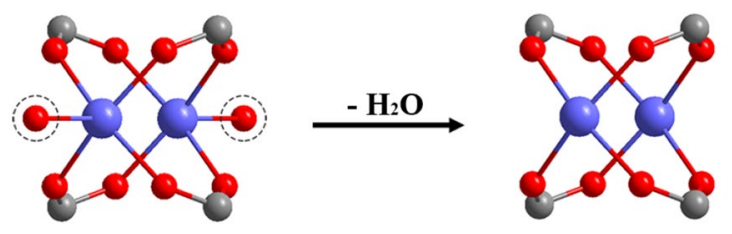

(b)
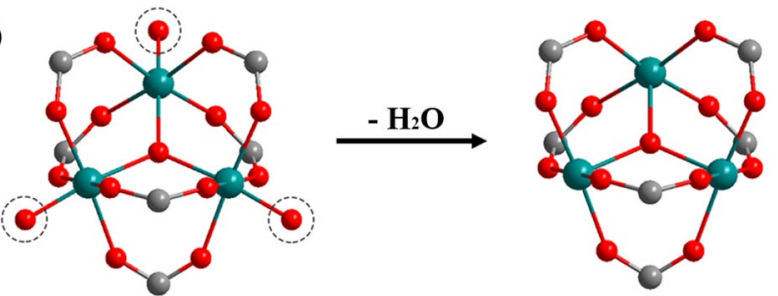

(c)
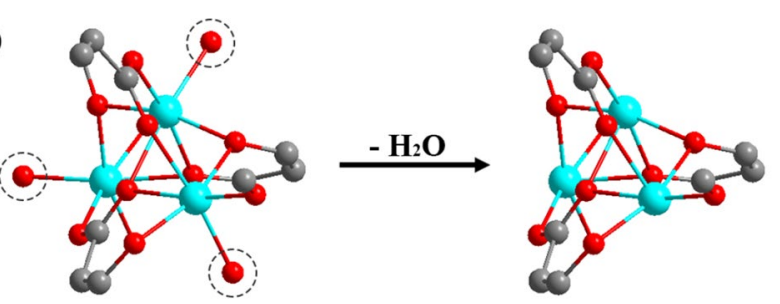

Fig. 1 Metal nodes of a Cu-BTC, b MIL-100/101, and c MOF-74 before and after dehydration. Moieties in the dashed circles may be removed after dehydration. Sphere model: gray $\mathrm{C}$; red $\mathrm{O}$; purple $\mathrm{Cu}$; green $\mathrm{Cr}$ or $\mathrm{Fe}$; blue $\mathrm{Mg}, \mathrm{Mn}, \mathrm{Fe}, \mathrm{Co}, \mathrm{Ni}, \mathrm{Cu}$, or $\mathrm{Zn}$ 
can be exposed after thermal activation, thereby exhibiting Lewis acidity (Fig. 1c) [38, 39].

The $\mathrm{Zr}_{6}\left(\mu_{3}-\mathrm{O}\right)_{4}\left(\mu_{3}-\mathrm{OH}\right)_{4}$ octahedron cluster is a secondary building unit in zirconium-based MOFs. Thereinto, six zirconium atoms constitute vertices of the octahedron, while four $\mu_{3}-\mathrm{O}$ atoms and four $\mu_{3}-\mathrm{OH}$ groups bulge from eight faces of the octahedron [40]. The number of organic linkers connected to each $\mathrm{Zr}_{6}$ cluster may vary from 12,8 to 6 (Fig. 2a). For example, in a perfect UiO-66/UiO-67 (i.e., $\mathrm{Zr}_{6}\left(\mu_{3}-\mathrm{O}\right)_{4}\left(\mu_{3}-\mathrm{OH}\right)_{4}(\mathrm{BDC})_{6} /$ $\mathrm{Zr}_{6}\left(\mu_{3}-\mathrm{O}\right)_{4}\left(\mu_{3}-\mathrm{OH}\right)_{4}(\mathrm{BPDC})_{6}$; BPDC $=$ biphenyl-4,4'dicarboxylate) crystal, 12 coordinative sites of the $\mathrm{Zr}_{6}$ node are fully coordinated with BDC/BPDC linkers $[40,41]$. By contrast, in NU-1000 (i.e., $\mathrm{Zr}_{6}\left(\mu_{3}-\mathrm{O}\right)_{4}\left(\mu_{3}-\mathrm{OH}\right)_{4}\left(\mathrm{H}_{2} \mathrm{O}\right)_{4}(\mathrm{OH}$ )$_{4}(\mathrm{TBAPy})_{2}$; TBAPy $=1,3,6,8$-tetrakis ( $p$-benzoate)pyrene), TBAPy linkers merely occupy eight coordination sites of the $\mathrm{Zr}_{6}$-octahedron, while the remaining four are terminated by four benzoate modulators exchangeable with water molecules or/and hydroxyl groups (i.e., terminal $\mathrm{Zr}-\mathrm{H}_{2} \mathrm{O}$ and $\mathrm{Zr}-\mathrm{OH})[41,42]$. The connection number of the $\mathrm{Zr}_{6}$ node of MOF-808 (i.e., $\left.\mathrm{Zr}_{6}\left(\mu_{3}-\mathrm{O}\right)_{4}\left(\mu_{3}-\mathrm{OH}\right)_{4}(\mathrm{BTC})_{2}(\mathrm{HCOO})_{6}\right)$ is even as low as six, where each $\mathrm{Zr}_{6}$ node is only connected by six trimesate linkers and remains the other six coordination sites occupied with weakly bonding species like formate [43,
44]. Similarly, these formate species could be substituted with a terminal-OH group or $\mathrm{H}_{2} \mathrm{O}[41,45]$. Consequently, the Brønsted acidities of the aforementioned $\mathrm{Zr}$-based MOFs could be endowed via dissociation of protons of $\mu_{3}-\mathrm{OH}$, terminal $\mathrm{Zr}-\mathrm{H}_{2} \mathrm{O}$, and $\mathrm{Zr}-\mathrm{OH}$ groups [46]. In addition, the coordinatively unsaturated $\mathrm{Zr}$ site featuring Lewis acidity [47] could also be produced via thermal removal of a water molecule in the terminal $\mathrm{Zr}-\mathrm{H}_{2} \mathrm{O}$ group or dehydration of two adjacent $\mu_{3}-\mathrm{OH}$ groups among $\mathrm{Zr}_{6}\left(\mu_{3}-\mathrm{O}\right)_{4}\left(\mu_{3}-\mathrm{OH}\right)_{4}[31$, 48, 49].

Alternatively, the acidity of MOFs is influenced by metal node modification of various ligands. For example, the weakly coordinated formate among MOF-808 is likely to be substituted by other ligands, e.g., triflate and sulfate, thereby enabling further acidity modification $[48,50]$. Lin et al. [51] developed a triflate modification strategy for the acidity improvement of MOF-808. Typically, the pristine MOF-808 was first washed with hot $\mathrm{HCl}$ solution to substitute the formate group with the hydroxyl group or water molecule. The resulting intermediate was further treated with trimethylsilyl triflate $\left(\mathrm{Me}_{3} \mathrm{SiOTf}\right)$ in benzene to substitute the hydroxyl and water species with $\mu_{2}-\mathrm{OTf}$ (Fig. $2 \mathrm{~b}$ ). Since the $\mathrm{OTf}^{-}$group is poorly nucleophilic and coordinated, it is likely to depart so that the modified $\mathrm{Zr}_{6}$ node is more
Fig. 2 a Zr $r_{6}\left(\mu_{3}-\mathrm{O}\right)_{4}\left(\mu_{3}-\mathrm{OH}\right)_{4}$ nodes in UiO-66/67, NU-1000, and MOF-808. Sphere model: green, $\mathrm{Zr}$; red, $\mathrm{O}$; white, $\mathrm{H}$. Reproduced with permission from Ref. [41]. Copyright 2016, the Royal Society of Chemistry. b Triflate modification of MOF-808. Sphere model: blue, $\mathrm{Zr}$; red, O; gray, C; white, $\mathrm{H}$; yellow, S; cyan, F. Reproduced with permission from Ref. [51]. Copyright 2019, American Chemical Society. c Sulfatemodification of MOF-808. Atom color: blue octahedron, $\mathrm{Zr}$; red, O; gray, C; yellow, S. Reproduced with permission from Ref. [50]. Copyright 2014, American Chemical Society (a)
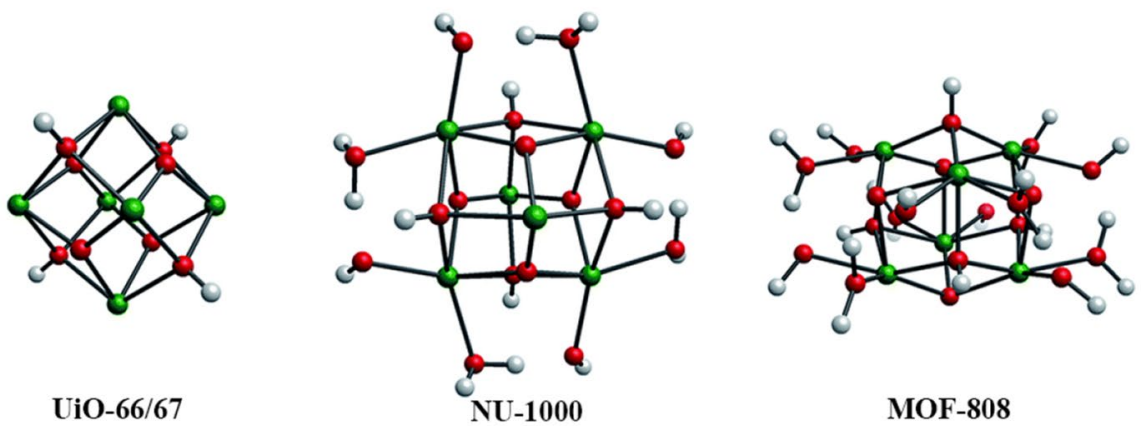

MOF-808

(b)

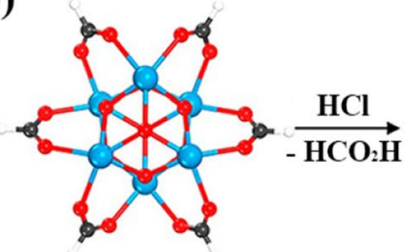

Zr-BTC
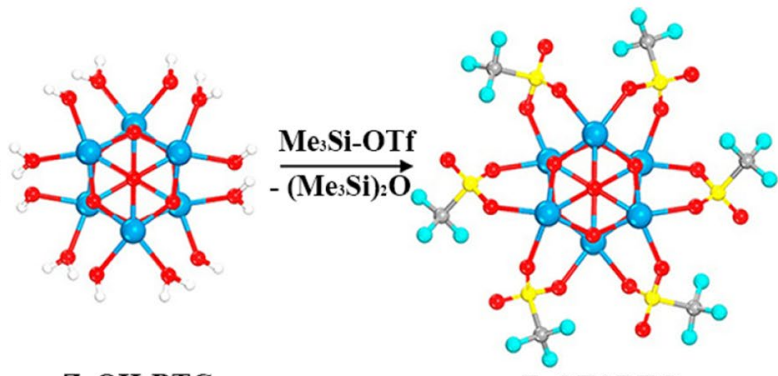

ZrOH-BTC

ZrOTf-BTC

(c)
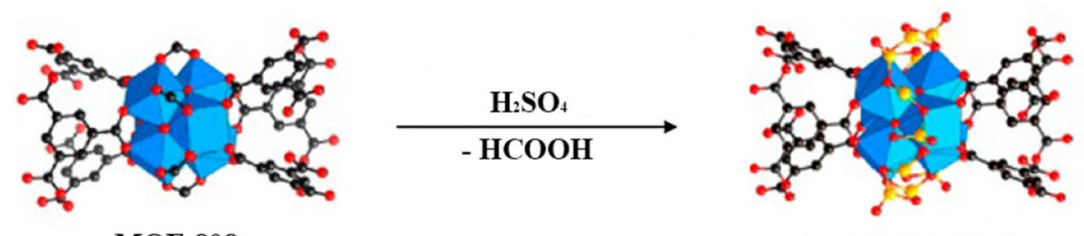

MOF-808-2.5SO 
Lewis acidic [51]. Also, the modification of metal nodes may be used for the enhancement of Brønsted acidity of MOFs. For instance, an MOF-based superacid (MOF-808$2.5 \mathrm{SO}_{4}$ ) (i.e., acidity stronger than $100 \%$ sulfuric acid) was prepared by immersing MOF-808 powder in aqueous $\mathrm{H}_{2} \mathrm{SO}_{4}$ solution, resulting in a material with a chemical composition of $\mathrm{Zr}_{6} \mathrm{O}_{5}(\mathrm{OH})_{3}(\mathrm{BTC})_{2}\left(\mathrm{SO}_{4}\right)_{2.5}\left(\mathrm{H}_{2} \mathrm{O}\right)_{2.5}$, in which the formate anions of pristine MOF-808 were completely replaced by sulfate anions (Fig. 2c). Because of the hydrogen bond between the sulfate and adsorbed water molecule, MOF-808$2.5 \mathrm{SO}_{4}$ has a Hammett acidity function $\left(\mathrm{H}_{0}\right) \leq-14.5$, indicating a higher acidity than pure $\mathrm{H}_{2} \mathrm{SO}_{4}\left(\mathrm{H}_{0}=-12\right)[50,52]$.

MOF acidity may also be influenced by the presence of defects. Modulator-assisted synthesis is a practical strategy to introduce and adjust the defects in MOFs $[53,54]$. As a typical example, trifluoroacetate is able to coordinate to the $\mathrm{Zr}_{6}$ octahedral cluster in place of the terephthalate linker, thus resulting in linker vacancies in the obtained UiO-66 materials. Subsequent thermal treatment not only dehydrated the $\mathrm{Zr}_{6}$ nodes by substituting two neighboring $\mathrm{OH}^{-}$ions with one $\mathrm{O}^{2-}$ bridge, but also removed the coordinated trifluoroacetate anions (Fig. 3a), namely the formation of coordinatively unsaturated sites. Furthermore, the number of unsaturated $\mathrm{Zr}$ sites could be obviously increased by the extra addition of hydrochloric acid during synthesis. On the one hand, as a strong Brønsted acid, $\mathrm{HCl}$ efficiently suppressed the deprotonation of terephthalic acid; on the other hand, the dissociated $\mathrm{Cl}^{-}$competed in bonding with $\mathrm{Zr}$ atoms with terephthalate. Jointly, more linker vacancies were produced, which could be thermally activated for exhibiting Lewis acidity in the resulting material [55].

Hemilabile linkers may be utilized to efficiently generate defects in MOFs as well. In a recent study, Voort et al. [49] added a hemilabile ligand, i.e., potassium 4-sulfobenzoic acid (PSBA), into a precursor solution of solvothermal synthesis of UiO-66. In comparison with conventionally prepared UiO-66, there are more defect sites produced in the hemilabile ligand-containing MOF (Hl-UiO-66) (Fig. 3b). Moreover, sulfuric acid treatment could further increase the number of defective sites to six per $\mathrm{Zr}_{6}$ cluster in the HlUiO-66- $\mathrm{SO}_{4}$, which is considered as the maximum allowed in a stable UiO-66 skeleton. After further thermal treatment, an extensively increasing number of Lewis acid sites could be acquired in $\mathrm{Hl}-\mathrm{UiO}-66$ and $\mathrm{Hl}-\mathrm{UiO}-66-\mathrm{SO}_{4}$ compared to normal UiO-66.

The sacrificial linker is another effective tool to produce defective sites in MOFs. For instance, ozone can selectively break the $\mathrm{C}=\mathrm{C}$ bond of ozone-active ligands (e.g., 4,4'-stilbene-dicarboxylic acid $\left(\mathrm{H}_{2} \mathrm{STI}\right)$ or 1,4-phenylenediacrylic acid $\left.\left(\mathrm{H}_{2} \mathrm{PDAC}\right)\right)$ among MOFs, resulting in the formation of linker-cleaved defects [56]. As an example, $\mathrm{H}_{2} \mathrm{STI}$ and 4,4'-azobenzene-dicarboxylic acid $\left(\mathrm{H}_{2} \mathrm{AZO}\right.$, an inert ligand toward ozone) were adopted as mixed linkers

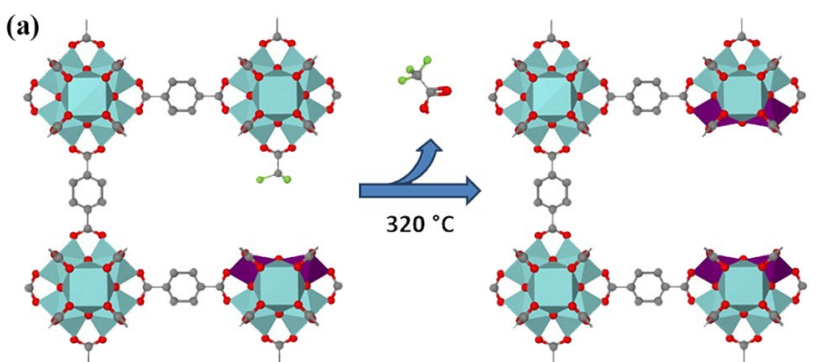

(b)

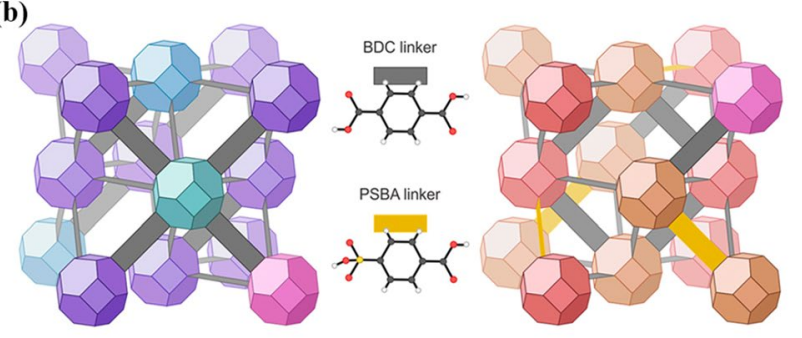

(c)

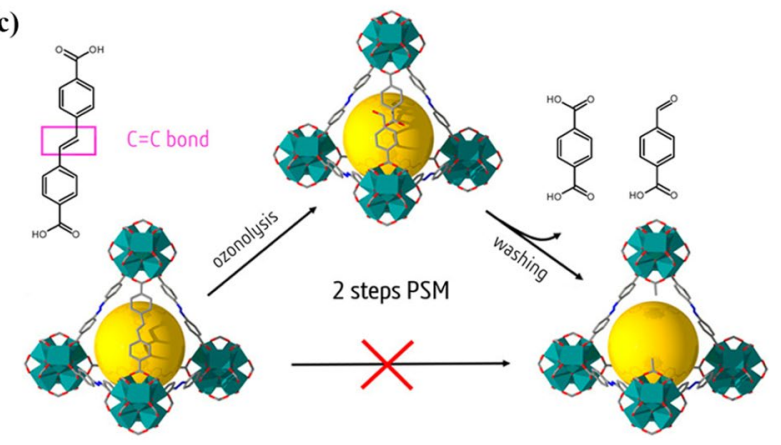

Fig. 3 a Trifluoroacetic acid modulated synthesis of UiO-66. Purple polyhedrons indicate defective $\mathrm{Zr}$ sites. Reproduced with permission from Ref. [55]. Copyright 2013, American Chemical Society. b Hemilabile linker assisted synthesis of UiO-66. Reproduced with permission from Ref. [49]. Copyright 2020, American Chemical Society. c Ozonolysis of the sacrificial linker in Zr-based MOFs. Reproduced with permission from Ref. [57]. Copyright 2018, American Chemical Society

to build a multivariate MOF featured with the classical $\mathrm{Zr}_{6}$ cluster. After treatment with ozone, the $\mathrm{C}=\mathrm{C}$ bond in the STI linker was cleaved to generate corresponding dangling terephthalic acid and 4-formylbenzoic acid, which were then readily removed by washing with acetic acid (Fig. 3c) [57].

Substituents on the organic linkers also have an impact on the acidic strength of connected metal nodes via an inductive effect. For instance, Lin et al. [58] reported two UiO-66 analogs, $\mathrm{Zr}_{6}$ - $\mathrm{fBDC}$ and $\mathrm{Zr}_{6}$-BDC-NO $\mathrm{N}_{2}$, with 2,3,5,6-tetrafluoroterephthalate and 2-nitroterephthalate as the typical terephthalate linkers, respectively. The electron paramagnetic resonance spectra of MOF-bound superoxide showed that the Lewis acidity of corresponding MOFs increases in the following order: $\mathrm{Zr}_{6}-\mathrm{fBDC}>\mathrm{Zr}_{6}-\mathrm{BDC}-\mathrm{NO}_{2}>\mathrm{UiO}-66$, in line with the electron-withdrawing ability of substituents: $-\mathrm{F}>-\mathrm{NO}_{2}>\mathrm{H}[59,60]$. 


\section{Functional Linkers as Acid Sites}

The organic linkers of MOFs are of great variety due to the multifarious and tunable shapes, dimensions, substituents, and coordination modes, thus allowing incorporation of multiple catalytic sites thereinto [61]. In particular, Brønsted acidity can be introduced into MOF materials accompanied with various acid functional groups, e.g., carboxylic acid and sulfonic acid. Generally, two common strategies, i.e., bottom-up synthesis and postsynthetic modification (PSM), have been developed to realize this target.

In a typical bottom-up scheme, ligands bearing desired functionalities are directly employed as building blocks for the hydro-/solvothermal preparation of MOFs, enabling quantitative and uniform incorporation of desired acid functional groups. MOF materials armed with dangling $-\mathrm{CO}_{2} \mathrm{H}$ groups could be directly prepared by using ligands containing additional carboxylic acid groups (Scheme 1a) [62-64]. For example, $\mathrm{UiO}-66(\mathrm{Zr})-\mathrm{CO}_{2} \mathrm{H}$ could be prepared via the one-pot solvothermal treatment of zirconyl nitrate and 1,2,4-tricarboxybenzene [65]. Compared with carboxylic acid, sulfonic acid is generally stronger in acidity, which is more catalytically active in reaction systems demanding high acidity. However, only MOFs with a robust skeleton against the strong sulfonic acid environment are feasibly constructed by directly using monosodium 2-sulfoterephthalic acid as the ligand precursor (Scheme $1 \mathrm{~b}$ ), such as $\mathrm{UiO}-66(\mathrm{Zr})-\mathrm{SO}_{3} \mathrm{H}$ [66], NUS-6(Zr, Hf) [67], and MIL-101(Cr)-SO ${ }_{3} \mathrm{H}$ [68].

The misconnection usually occurred in the bottom-up synthesis due to the potential coordination between metal nodes and additional acid substituent groups dangling on the ligands, causing low crystallinity of desired MOF products or forming side products of unknown structure. In sharp contrast, the PSM strategy can overcome such drawbacks effectively [69]. In a prototype, highly crystalline parent MOFs are first prepared using raw ligands with the potential for chemical modification. Then, desired functional groups are incorporated into the presynthesized skeletons via substitution or transformation from the precursive functional groups $[25,70]$. For instance, incorporation of a carboxylic acid group into MOFs can be done either with carboxylic anhydride by reaction with hydroxy/amino substituents [71, 72] or by oxidation of the formyl group inside the MOF pores (Scheme 2a) [73]. As for sulfonic acid groups, they can be directly attached to terephthalate-based MOFs by treating the bare aromatic skeleton with chlorosulfonic acid [74, 75], be incorporated via sulfonation decoration of aminosubstituted MOFs [76], or be obtained from oxidation of mercaptan-substituted MOFs (Scheme 2b) [77].

\section{Guest Species Supported by MOFs as Acid Sites}

Compared with conventional catalyst supporters (e.g., polymers, zeolites, carbon materials), MOFs possess extraordinarily large specific surface areas and high pore volumes. In addition, their inner pore structures and properties can be easily tuned by various methods [78]. Combining both advantages, the accommodation of acid guest species inside the MOF pores is anticipated to enhance the acidity of pristine MOF materials and address the leaching and
Scheme 1 Bottom-up synthesis of MOFs with a dangling carboxylic acid and $\mathbf{b}$ sulfonic acid groups (a)

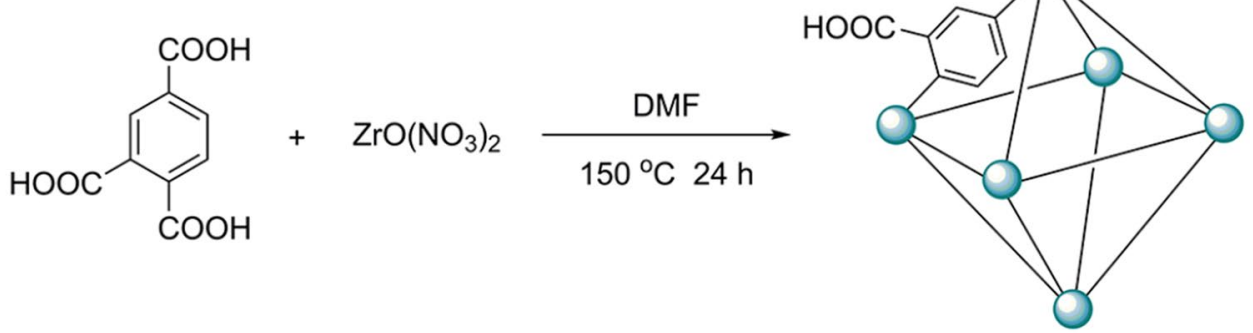

(b)<smiles>O=C(O)c1ccc(C(=O)O)c(S(=O)(=O)[O-])c1</smiles>

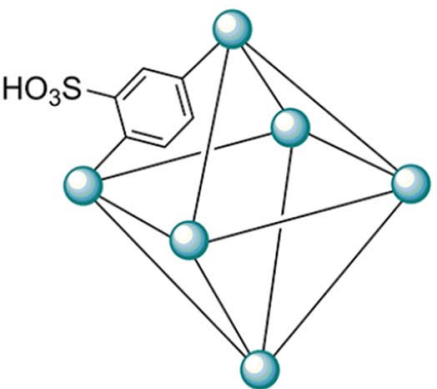

$=\mathrm{Zr}_{6}$ cluster 
Scheme 2 Postsynthetic modification routes to incorporate $\mathbf{a}$ carboxylic acid and $\mathbf{b}$ sulfonic acid groups (a)
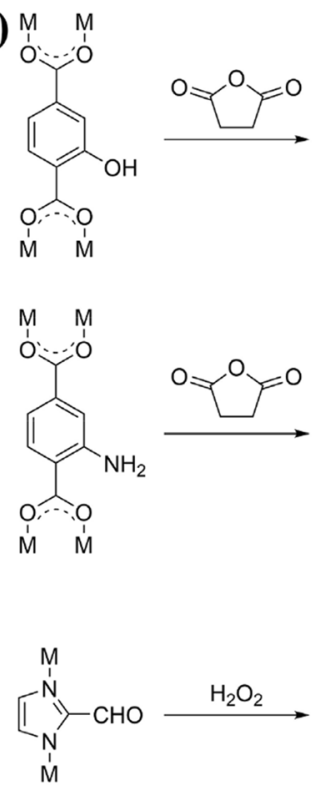

deactivation of free guest species by the confinement effect [79-81].

Due to their strong Lewis/Brønsted acidic nature, POMs are a major type of guest species for improving the acidity of MOFs. As early as 2003, Naruke and co-workers [82] proposed a one-pot hydrothermal preparation strategy to incorporate phosphotungstic acid (PTA) into MOFs. Henceforth, a number of POM-MOF composites have sprung up during the nearly past two decades [83-85]. As a typical example, a series of Keggin-type POMs were incorporated into HKUST-1 by one-step synthesis using $\mathrm{Cu}\left(\mathrm{NO}_{3}\right)_{2}$, BTC, and corresponding POMs. Interestingly, the corresponding POMs were found to be selectively accommodated into the

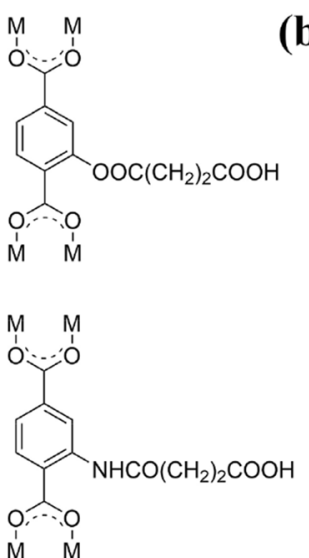

(b)

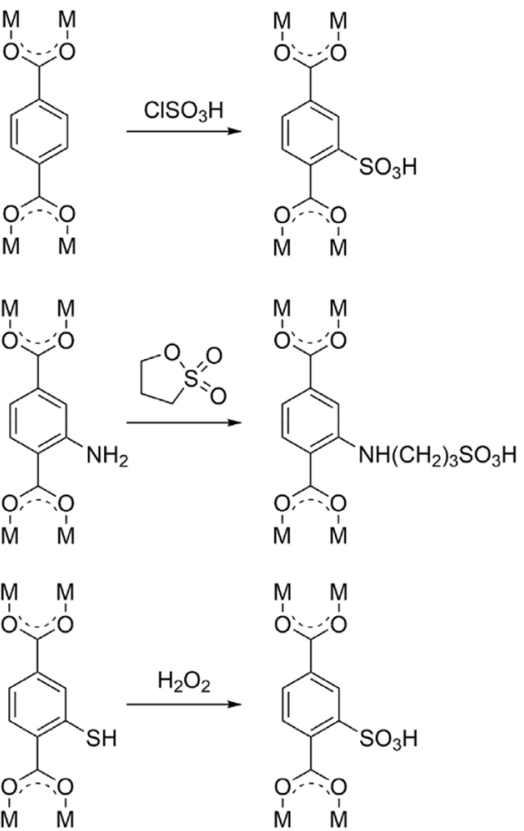

larger pore of HKUST-1, thereby leaving the smaller pore empty for other incoming catalysis substrates (Fig. 4) [83].

\section{Application in Biomass Upgrade}

As mentioned before, acid catalysis has been extensively applied in biomass utilization. For example, small hydrocarbons, such as cellobiose, xylose, and glucose, can be produced from cellulose biomass by Brønsted acid-catalyzed hydrolysis. With a Lewis acid, glucose can undergo isomerization or epimerization to yield fructose or mannose, respectively. Moreover, fructose can be further converted to

Fig. 4 Structural illustration of MOF-supported POM. Reproduced with permission from Ref. [83]. Copyright 2009, American Chemical Society
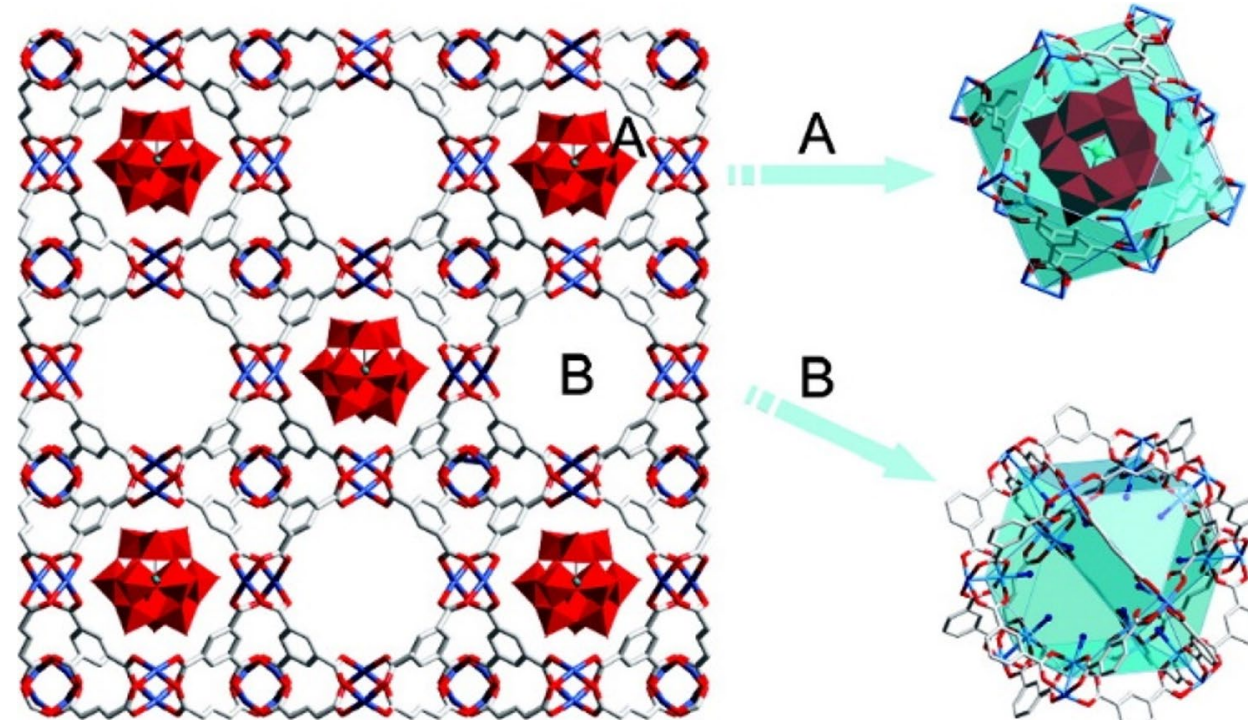

B

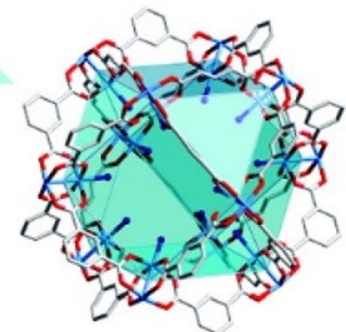


5-HMF, levulinic acid, and alkyl levulinates on Brønsted acid sites (Scheme 3 ) [86, 87]. Because of the complexity of these reactions, in some cases, a synergistic or tandem catalyst involving both Lewis acid and Brønsted acid sites is highly needed $[1,88,89]$.

\section{Transformation of Cellulose}

Cellulose, as a naturally abundant polymer consisting of 7000-15,000 glucose units, is an ideal starting biomass for the synthesis of high value-added chemicals [1]. Compared with oligosaccharides and disaccharides (e.g., cellobiose and sucrose), however, it is still a huge challenge to efficiently hydrolyze cellulose due to its poor contact with catalyst moieties arising from the much larger size of cellulose as well as its interlinked molecular structure [90].
The study of Brønsted acid-rich MOFs on catalyzing cellulose transformation dates to 2011. Kitagawa et al. [68] prepared a sulfo-modified MIL-101(Cr) via a bottom-up synthesis method. According to the elemental analysis characterization result, nearly two-thirds of sulfo groups dangling on the resulting MOF products are in the Brønsted acid form that can easily release protons for catalysis application, while others are in the anionic sulfonate form to maintain electric neutrality. In the hydrolysis of cellulose (Fig. 5), as-resulted sulfo-modified MOFs hydrolyzed 5.3\% of the cellulose to saccharides, including cellobiose, xylose, and glucose at $120^{\circ} \mathrm{C}$ after $3 \mathrm{~h}$.

Moreover, MOF-based composites can even promote the tandem transformation of cellulose to more valuable chemicals. For instance, $\mathrm{Ga}_{2} \mathrm{O}_{3}$-modified UiO-66 was applied as the catalyst for the transformation of cellulose to levulinic
Scheme 3 Acid catalyzed transformation from glucose and its derivatives
Fig. 5 Cellulose hydrolysis on solid acid materials. Reproduced with permission of Ref. [68]. Copyright 2011, Wiley$\mathrm{VCH}$

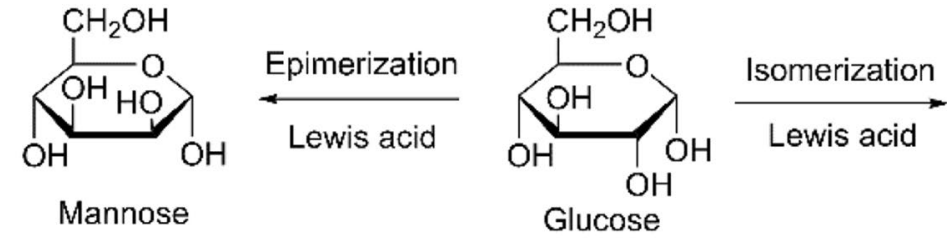

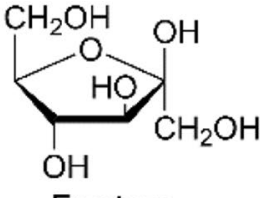

Fructose

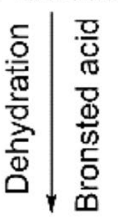

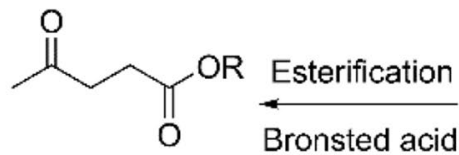

Alkyl Levulininate<smiles>CC(=O)CCC(=O)O</smiles>

$\frac{\text { Rehydration }}{\text { Bronsted acid }}$ Levulinic acid<smiles>O=Cc1ccc(CO)o1</smiles>

5-HMF

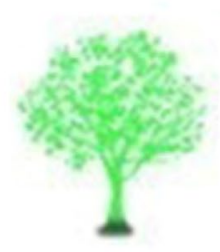

$[\sqrt{O H}]_{n}^{\mathrm{OH}_{2}^{\mathrm{OH}}}$

Cellulose

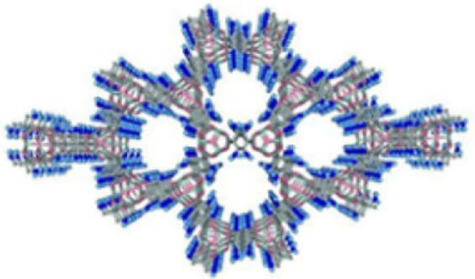

Solid Acid

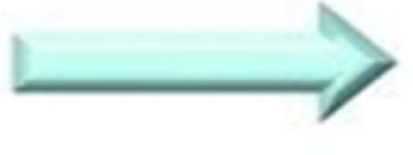

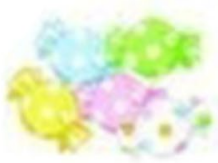

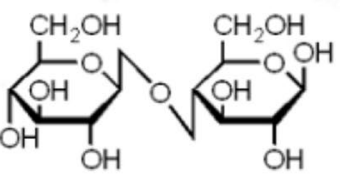

Cellobiose

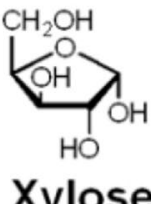

Xylose Glucose 
acid. The tandem process contains a series of steps, i.e., cellulose hydrolysis, glucose isomerization, fructose dehydration, and 5-HMF dehydration. The highly robust UiO-66 skeleton ensured the endurance of the composite catalyst at ultra-high operation temperature $\left(240{ }^{\circ} \mathrm{C}\right)$. Meanwhile, as-incorporated $\mathrm{Ga}_{2} \mathrm{O}_{3}$ offered extra moderate acidity. In combination, the $\mathrm{Ga}_{2} \mathrm{O}_{3}$-UiO-66 composite exhibited significantly enhanced catalytic performance (32\% yield) in comparison with pristine UiO-66 (12\% yield) [91].

\section{Transformation of Monosaccharides}

\section{Glucose to Fructose/Mannose}

As the basic constitutional unit of cellulose and starch, glucose is the most widespread monosaccharide in organisms and, hence, is commonly used for manufacturing other sugars and fine chemicals. It has been well accepted that the isomerization of glucose to fructose can be efficiently promoted by Lewis acid catalysts (Scheme 3). Therefore, the open metal sites existing in MOFs can serve as active centers. Matsuda et al. [92] investigated the catalytic effect of two Cr(III)-based MOFs, MIL-100 and MIL-101, in aqueous media at $100{ }^{\circ} \mathrm{C}$. Although both MOFs contained the same $\mathrm{Cr}_{3} \mathrm{O}$ cluster as Lewis acid sites, the fructose yield obtained by MIL-101 (12.6\%) was much higher than that by MIL-100 (3.8\%) because of the larger pore window of MIL-101. Furthermore, the nitro-substituted MIL-101 showed a further enhanced yield for fructose (18.4\%) under other identical conditions by taking advantage of the strong electron-withdrawing $-\mathrm{NO}_{2}$ group close to the active Lewis $\mathrm{Cr}_{3} \mathrm{O}$ site.

Interestingly, the fructose to mannose product ratio could be even adjusted by using a Zr-based solid catalyst but of a different structure. For example, in aqueous solution and at $100{ }^{\circ} \mathrm{C}$, UiO-66( $\left.\mathrm{Zr}\right)$ gave the formation products of fructose and mannose in yields of $5 \%$ and $6.3 \%$ via the isomerization and epimerization pathways, respectively [93]. Similarly, MOF-808(Zr) produced a mixture of fructose and mannose as well, but the selectivity of mannose was lower than that of UiO-66(Zr). At $90{ }^{\circ} \mathrm{C}$, the fructose/ mannose ratios offered by MOF-808(Zr) and UiO-66(Zr) were about 1.5 and 0.6 , respectively. In contrast, $\mathrm{Zr}$ - $\beta$ zeolite yielded fructose as a preferable product (fructose/mannose ratio $=5)$. As ${ }^{13} \mathrm{C}$ nuclear magnetic resonance spectroscopy revealed, glucose transformation may proceed through two separate routes over Lewis acid catalysts: a 1,2-intramolecular hydride shift to produce fructose and 1,2-intramolecular carbon shift to produce mannose. Density functional theory (DFT) calculations suggested that the activation energy of the 1,2-intramolecular hydride shift is similar among the three Zr-based materials. However, as for the 1,2-intramolecular carbon shift, the order of activation energy is
UiO-66(Zr) $<$ MOF-808(Zr) $<<\mathrm{Zr}-\beta$ zeolite, consistent with the corresponding selectivity order toward glucose [94].

Furthermore, the influence of crystalline defects on catalytic performance was explored. Two UiO-66-type materials, UiO-66-D(1d) and UiO-66-D(3d), were prepared by changing the crystallization duration ( 1 day and 3 days, respectively) of solvothermal synthesis. UiO-66-D(1d) possesses approximately equal amounts of linker-missing and cluster-missing defects, while UiO-66-D(3d) has more linkermissing defects but fewer cluster-missing defects. Under the same catalytic conditions, a higher percentage of glucose was produced over UiO-66-D(1d) (47\%) than that of UiO$66-\mathrm{D}(3 \mathrm{~d})(34 \%)$, indicating that the cluster-missing defect is more favorable for the formation of the glucose product [95].

\section{Fructose to 5-HMF}

As a key intermediate in the transformation of sugar to value-added fine chemicals, 5-HMF can be obtained via Brønsted acid-catalyzed fructose dehydration (Scheme 3) $[96,97]$. Despite the challenge that the coordination bond between the metal node and organic linker is vulnerable under strong acidity, a number of MOFs bearing Brønsted acid sites have been developed and applied in sugar transformation. For example, a PTA/MIL-101 composite formed via encapsulating PTA into MIL-101(Cr) was tested as a catalyst for fructose dehydration in the solvent of 1-ethyl3 -methylimidazolium chloride ([EMIM]Cl) at $80^{\circ} \mathrm{C}$. After optimizing the loading amount of PTA, a maximal 5-HMF yield of up to $63 \%$ was obtained. Although the 5-HMF selectivity over PTA/MIL-101 (74\%) was slightly lower than that over free PTA (92\%), it could be easily separated and recycled from the reaction mixture [98].

Sulfonic acid-modified MOFs, e.g., MIL-101(Cr)- $\mathrm{SO}_{3} \mathrm{H}$, UiO-66( $\mathrm{Zr})-\mathrm{SO}_{3} \mathrm{H}$, and MIL-53( $\left.\mathrm{Al}\right)-\mathrm{SO}_{3} \mathrm{H}$, were also evaluated as solid acid catalysts for converting fructose to 5-HMF. The sulfonated materials were prepared by PSM of corresponding parent $\mathrm{MOFs}$ using $\mathrm{ClSO}_{3} \mathrm{H}$, and the grafting amount of $-\mathrm{SO}_{3} \mathrm{H}$ was adjusted by changing the dosage of $\mathrm{ClSO}_{3} \mathrm{H}$. The corresponding 5-HMF yield increased as the grafting amount of the sulfo group increased. Particularly, when the grafting ratio of the $-\mathrm{SO}_{3} \mathrm{H}$ group was relatively low $(\leq 9.5 \%)$, the turnover frequency of glucose was linearly dependent on the amount of grafted $-\mathrm{SO}_{3} \mathrm{H}$ site regardless of the type of parent MOF [74].

NUS-6 is a $\mathrm{Zr} / \mathrm{Hf}$-based MOF adopting the same metal node but using 2-sulfoterephthalate instead of terephthalate as the organic linker compared with UiO-66 (Fig. 6). Acid-base titration indicated that, despite containing the same amount of sulfo group, NUS-6(Hf) possesses stronger Brønsted acidity than NUS-6(Zr), probably due to the stronger bonding between $\mathrm{Hf}$ and $\mu_{3}-\mathrm{OH}$ in the $\mathrm{Hf}_{6}\left(\mu_{3}-\mathrm{O}\right)_{4}\left(\mu_{3}-\mathrm{OH}\right)_{4}$ cluster, which endows $\mu_{3}-\mathrm{OH}$ with 
Fig. 6 Structure and catalytic application of NUS-6. Reproduced with permission from Ref. [67]. Copyright 2016, American Chemical Society

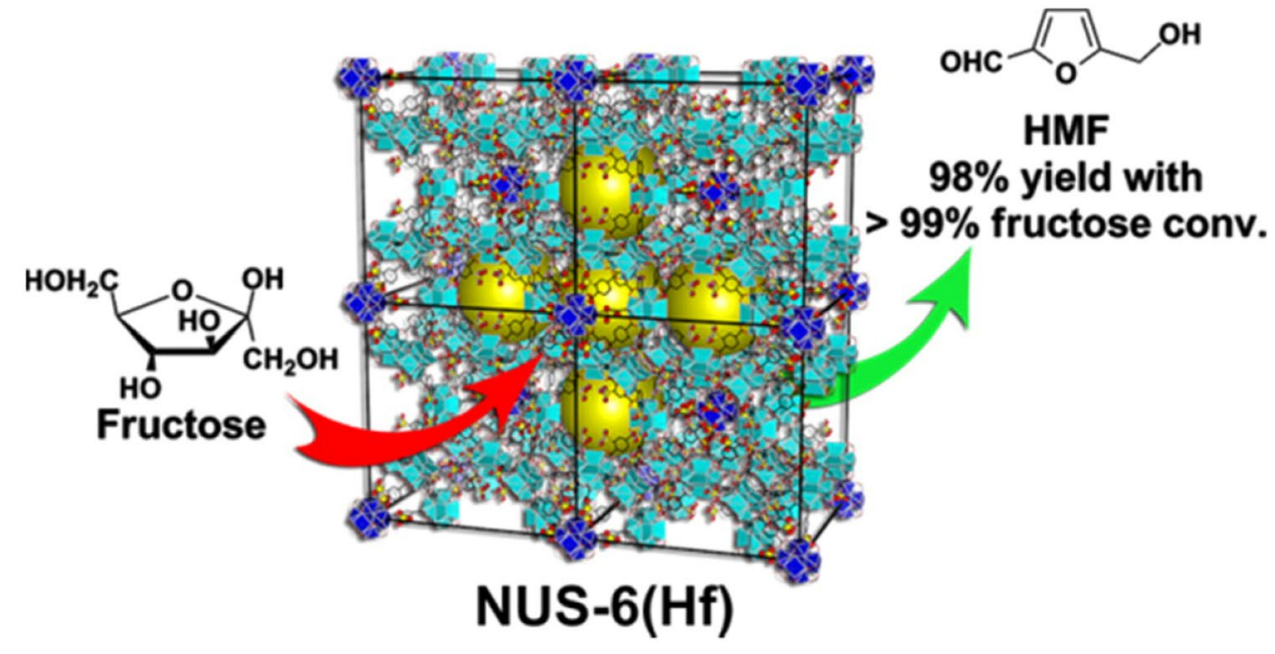

stronger proton dissociability. Both MOFs were evaluated in fructose dehydration in DMSO. In the presence of NUS$6(\mathrm{Zr})$, nearly full conversion (>99\%) and $84 \%$ selectivity toward 5-HMF were obtained after $1 \mathrm{~h}$ at $100{ }^{\circ} \mathrm{C}$. NUS-6 (Hf) exhibited better performance ( $>99 \%$ conversion and $98 \%$ selectivity) under identical conditions. The stronger Brønsted acidity of NUS-6(Hf) was assigned to its superior catalytic performance to a certain extent. In addition, the pore size of MOF catalysts also had an impact on the selectivity performance. It has been well accepted that the production of 5-HMF relies on the furanose-type fructose (fructofuranose) reactant, while the by-product (e.g., humin) is formed from linear fructose, which is generated from the isomerization of fructofuranose. As the micropore size of NUS-6(Hf) $(5.5 \AA)$ was larger than the dimension of fructofuranose $(\sim 4 \AA)$, fructofuranose could be confined in the micropores of NUS-6(Hf) so that its isomerization to the linear form $(\sim 4 \AA)$ could be suppressed, leading to the higher selectivity toward 5-HMF. Due to the larger micropore size (6 ̊)), NUS-6(Zr) showed a relatively weak confinement effect and therefore inferior 5-HMF selectivity [67].

\section{Glucose to 5-HMF}

It is more economical to produce 5-HMF from glucose in a cascade catalysis system due to the extensive source of glucose, in which acid catalyst bearing dual Lewis and Brønsted acid sites are required (Scheme 3). Bao et al. [99] applied MIL-101(Cr)- $\mathrm{SO}_{3} \mathrm{H}$ in glucose to $\mathrm{HMF}$ cascade transformation (Fig. 7). With prolonging the reaction time, the concentration of fructose in the system first increased and then decreased, demonstrating that the transformation indeed proceeded through the isomerization-dehydration pathway. Interestingly, the presence of water is a two-edged sword in this reaction. On the one hand, a small amount of water could induce the formation of $\mathrm{Cr}-\mathrm{OH}$ species, which is conducive to 1,2-hydride transfer in the glucose isomerization step. On the other hand, water molecules might compete with glucose in coordinating with the unsaturated $\mathrm{Cr}$ sites in the glucose isomerization step, thereby obstructing the isomerization procedure. Hence, only a modest yield of 5 -HMF was obtained in pure water $(12.3 \%)$ or polar aprotic solvent (26.2\%, in $\gamma$-valerolactone), but a significantly
Fig. 7 MIL-101(Cr)- $\mathrm{SO}_{3} \mathrm{H}$ as a catalyst for the conversion from glucose to 5-HMF. Reproduced with permission from Ref. [99]. Copyright 2016, American Institute of Chemical Engineers

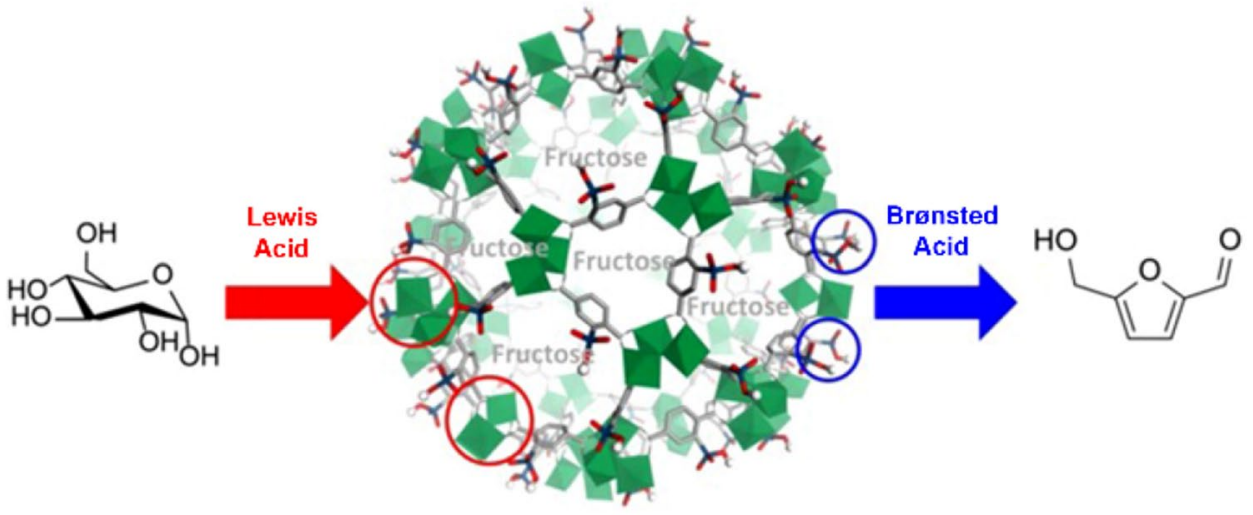


improved yield (39.8\%) was obtained in the mixture of water and $\gamma$-valerolactone $(1: 9, \mathrm{w} / \mathrm{w})$.

Additionally, Zr-MOF-based solid acid was potentially active in the catalysis of glucose to 5-HMF transformation. Yabushita et al. [100] used NU-1000 as the Lewis acid catalyst, and $60 \%$ glucose conversion and $2.3 \%$ yield toward 5-HMF were obtained in water. In order to improve the performance, modification of NU-1000 with Brønsted phosphoric acid was performed. After a full phosphoric acid decoration of $\mathrm{Zr}_{6}$ nodes, the resultant $\mathrm{PO}_{4} / \mathrm{NU}(\mathrm{eq})$ with mere Brønsted acidity showed elevated 5-HMF yield (5.9\%) but reduced glucose conversion (17\%), demonstrating the necessity of Lewis acidity (i.e., unsaturated metal sites) in the catalysis. On the other hand, moderate glucose conversion $(50 \%)$ and the highest 5-HMF yield (15\%) were achieved when only half of $\mathrm{Zr}_{6}$ 's unsaturated sites were modified $\mathrm{PO}_{4} /$ NU(half).

Lanthanide-based MOFs have also been widely applied in catalysis due to their Lewis acidity [101]. Degirmenci and co-workers [102] designed an ytterbium (Yb)-based MOF, $\mathrm{Yb}_{6}(\mathrm{BDC})_{7}(\mathrm{OH})_{4}\left(\mathrm{H}_{2} \mathrm{O}\right)_{4}$, in which $\mathrm{Yb}(\mathrm{III})$ ions were coordinated by terephthalates, hydroxyl bridges, and water molecules. Especially, the weakly coordinated water molecules could be removed by heating at $200{ }^{\circ} \mathrm{C}$, and the resultant unsaturated sites could serve as Lewis acid centers. Meanwhile, the bridging hydroxyl groups possess Brønsted acidity. In the catalytic conversion of glucose to HMF in an aqueous solution, the activated Yb-based MOFs offered 5 -HMF with $65 \%$ selectivity and $28 \%$ glucose conversion. Moreover, the catalyst could be reused for four cycles without a significant decrease in 5-HMF yield.

\section{Glucose to Levulinic Acid}

Levulinic acid and its derivatives have been employed as components of biofuels and additives for the functionalization of polymers. It has been proposed that glucose may sequentially undergo isomerization, dehydration, and subsequent rehydration to yield levulinic acid via a synergistic catalysis way via using both Lewis and Brønsted acids (Scheme 3).

In a recent study, PTA was incorporated into the pores of MIL-100(Fe), and the resultant composite $\left(\mathrm{PM}_{2}\right)$ was further decorated with lysine $\left(\right.$ Lys- $\left.\mathrm{PM}_{2}\right)$ for conversion of glucose to levulinic acid (Fig. 8). After systematic evaluation, the conversion of glucose and selectivity of levulinic acid were both ranked in the order of Lys- $\mathrm{PM}_{2}>\mathrm{PM}_{2}>$ bare MIL-100(Fe). It has been suggested that PTA can enhance the Brønsted acidity of MOF materials, thus increasing the catalytic activity in fructose dehydration and 5-HMF rehydration. In addition, the introduced amino group from lysine may also facilitate the isomerization of glucose to fructose. Furthermore, the carboxyl group of lysine can enhance the interaction between the substrate and catalyst via the formation of hydrogen bonding, thus also leading to improved catalytic performance [103].

\section{Glucose to Alkyl Lactate}

Alkyl lactates are green solvents and key precursors for the preparation of degradable polylactide resin [5]. Acidcatalyzed conversion of sugar to alkyl acetate was proposed by enjoying the low cost of sugar and its abundant source in nature. For example, glucose to methyl lactate transformation consists of multiple reaction steps in sequence: isomerization of glucose, the retro-aldol reaction of fructose, dehydration of glyceraldehyde/dihydroxylacetone, formation of pyruvaldehyde methyl hemiacetal, and 1,2-hydride shift of hemiacetal, in which glucose isomerization, retro-aldol reaction, and the 1,2-hydride shift could be accelerated by Lewis acid catalyst (Scheme 4) [104].
Fig. 8 Lys-PM $\mathrm{PM}_{2}$ composite as a catalyst for the conversion from glucose to levulinic acid. Reproduced with permission from Ref. [103]. Copyright 2019, Elsevier

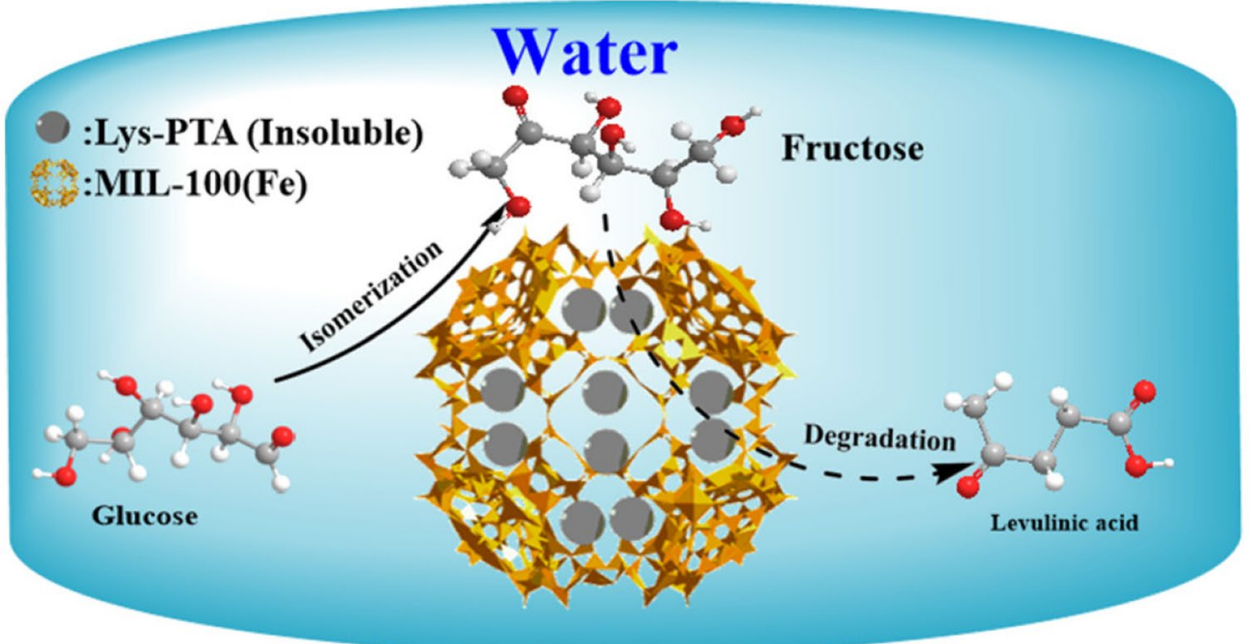


Scheme 4 Acid catalyzed conversion from glucose to methyl lactate

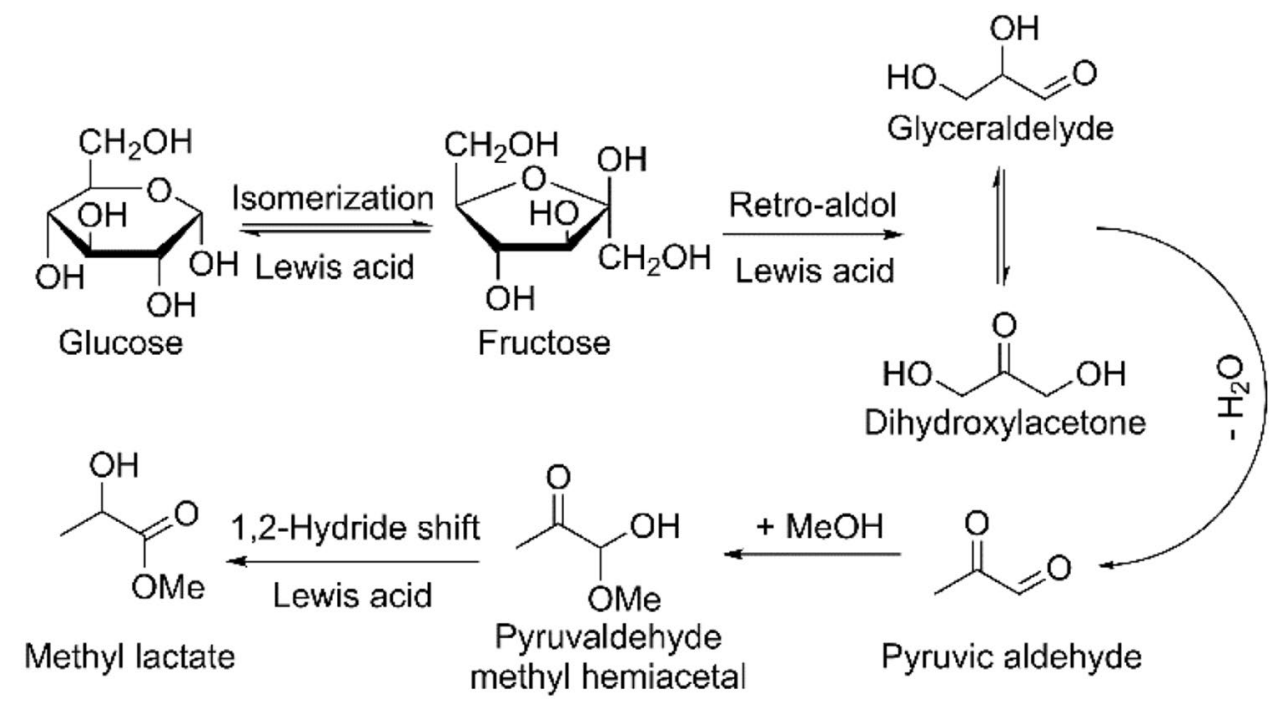

M-MOF-74 materials ( $\mathrm{M}=\mathrm{Co}, \mathrm{Ni}, \mathrm{Mg}, \mathrm{Zn}$ ) were used to catalyze the aforementioned tandem reactions in methanol. A higher yield toward methyl lactate $(27 \%)$ was obtained over Mg-MOF-74 than others (16\%-20\%) under identical conditions, probably attributed to its relatively stronger Lewis acidity and larger surface area [105]. Moreover, comparable catalytic performances were reported over ZIF-8 (Zn(MeIM) $)_{2}$, MeIM = 2-methyl imidazolate $)(19.7 \%$ glucose to methyl lactate yield) and partially tin-exchanged MIP-177-LT $\left(\mathrm{Ti}_{12} \mathrm{O}_{15}(\mathrm{mdip})_{3}(\mathrm{HCOO})_{6}\right.$, mdip = 3,3',5,5'-tetracarboxyldiphenylmethane) (21.8\% glucose to methyl lactate yield) at $160{ }^{\circ} \mathrm{C}$ for $20 \mathrm{~h}[106,107]$.

\section{Xylose to Furfural}

Similar to the glucose to HMF conversion mentioned above, xylose can be transformed into furfural via Lewis acid-catalyzed isomerization followed by Brønsted acid-catalyzed dehydration (Scheme 5) [108, 109]. Since pristine MIL101(Cr), limited by its relatively low Brønsted acidity, only displayed unsatisfied catalytic performance in the application of xylose to furfural transformation, several types of MIL-101(Cr)-based materials with dual-acid sites were developed to promote catalytic conversion. For example, MIL-101(Cr)- $\mathrm{SO}_{3} \mathrm{H}$ via installing strong Brønsted $-\mathrm{SO}_{3} \mathrm{H}$ showed a striking improvement in the yield of furfural in comparison to pristine MIL-101(Cr) (from 30 to $64.7 \%$ ) [110]. Furthermore, a composite combining MIL-101(Cr) and tin(IV) phosphate (SnP) was also prepared for further enhancing the yield of furfural. By optimizing the SnP loading amount, the obtained SnP-MIL-101(Cr) composite gave a much higher furfural yield $(86.7 \%)$ than both pristine MIL101(Cr) (40.3\%) and mesoporous SnP (48\%) [111].

\section{Transformation of Platform Molecules}

Alkyl levulinates, extensively used as fragrances, plasticizers, and biofuel additives, are generally synthesized by acid-catalyzed Fischer esterification of levulinic acid with alcohols. Due to the strong Lewis acidity of the $\mathrm{Zr}$ cluster, UiO-66 gave comparable or even better performance than several types of commonly used solid acid catalysts (e.g., Amberlyst-15, H-MCM-22, H-ZSM-5, sulfated titania, and zirconia) in the application of levulinic acid esterification with ethanol and butanol. Levulinates with longer alkyl chains (e.g., lauryl, cetyl, and stearyl) were also successfully obtained, but corresponding reaction rates offered by $\mathrm{UiO}$ 66 obviously declined due to the severe adsorption of bulky reactants and products onto the external surface of UiO-66 $[112,113]$. Furthermore, UiO-66- $(\mathrm{COOH})_{2}$ was applied in the esterification of levulinic acid with ethanol. The yield of ethyl levulinate reached $23.9 \%$ after a reaction of $8 \mathrm{~h}$
Scheme 5 Tandem transformation from xylose to furfural catalyzed by acid

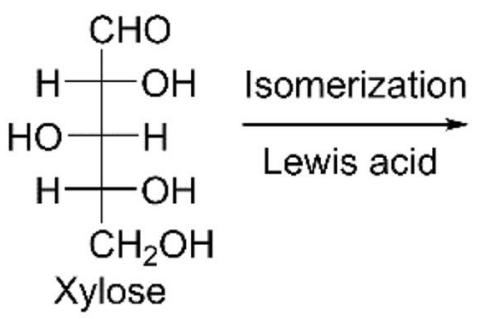

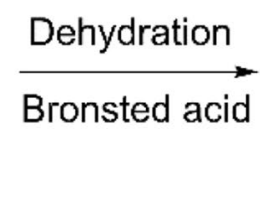<smiles>O=Cc1ccco1</smiles>

Furfural 
(and $97.0 \%$ after $24 \mathrm{~h}$ ), and only a slight deterioration was observed after five continuous catalysis cycles. Such performance achieved by UiO-66-(COOH $)_{2}$ was better than bare UiO-66(Zr) $(4.2 \%$ yield after $8 \mathrm{~h})$, terephthalic acid $(2.6 \%$ yield after $8 \mathrm{~h}$ ), and their physical mixture $(10.8 \%$ yield after $8 \mathrm{~h}$ ), implying that the dangling carboxyl groups and unsaturated $\mathrm{Zr}$ nodes among $\mathrm{UiO}-66-(\mathrm{COOH})_{2}$ may facilitate the esterification process in a synergistic manner. As DFT calculations suggested, levulinic acid is first adsorbed onto the open $\mathrm{Zr}$ site of UiO-66 or UiO-66- $(\mathrm{COOH})_{2}$ and then is subjected to nucleophilic attack from an ethoxyl group bonding onto a neighboring $\mathrm{Zr}$ atom. At this stage, the free $-\mathrm{COOH}$ group among UiO-66-(COOH $)_{2}$ could promote the leaving of carboxylic-OH of adsorbed levulinic acid, thus reducing the energy barrier of the esterification process (Fig. 9) [62].

5 -HMF is an important saccharide-derived molecule that can be further transformed into other useful chemicals, e.g., alkyl levulinates and 5-alkoxymethylfurfurals. As mentioned above, ethyl levulinate (EL) is widely applied in fine-chemical manufacturing. In addition, 5-ethoxymethylfurfural (EMF) is considered a candidate for biofuel due to its high energy density. Both EMF and EL can be obtained via Brønsted acid-catalyzed reaction between 5-HMF and ethanol. [Cu-BTC][HPM], a composite in which phosphomolybdic acid hydrate (HPM) is anchored in the pores of $\mathrm{Cu}-\mathrm{BTC}$, was employed in promoting this reaction. NENU-5 showed good catalytic performance (43.7\% EMF yield, 7.6\% EL yield), which was comparable to free HPM (44.6\% EMF yield, $8.9 \%$ EL yield). On the other hand, compared with homogeneous HPM, [Cu-BTC][HPM] can be easily recycled and reused without significant loss of yield [114].

Furfuryl alcohol is a key intermediate for the manufacture of fine chemicals, including EL and $\gamma$-valerolactone [115]. It is commercially producible via hydrogenation of furfural over noble metals and their complexes [116]. Despite the high catalytic activity, these materials usually suffer from exorbitant costs, limited sources. Besides, the storage and operation of $\mathrm{H}_{2}$ are dangerous, and it is inevitable to produce undesired by-products due to the accompanying hydrogenation of the $\mathrm{C}=\mathrm{C}$ bond. This can be avoided by using an alternative method, Lewis acid-promoted transfer hydrogenation using isopropanol as the reductant (i.e., Meerwein-Ponndorf-Verley reduction) [117]. A number of Zr-based MOFs (UiO-66, DUT-52, UiO-67, DUT-67, and MOF-808) featuring different organic ligands and connecting modes were investigated as Lewis catalysts for transfer hydrogenation. UiO-66, DUT-52, and UiO-67 consist of the 12-connected octahedral $\mathrm{Zr}_{6}$ node, while DUT-67 and MOF-808 are composed of the 8- and 6-connected $\mathrm{Zr}_{6}$ nodes, respectively. In the transfer hydrogenation, MOF- 808 showed higher furfuryl alcohol yield (66.4\%) than DUT67 (13.5\%), whose performance was higher than UiO-66, DUT-52, and UiO-67 $(\leq 1.3 \%)$. The performance sequence of these MOFs followed well with their number of coordinatively unsaturated sites per $\mathrm{Zr}_{6}$ node, namely for MOFs with a smaller coordination number, the $\mathrm{Zr}_{6}$ node showed higher catalytic activity. Furthermore, activation using boiled methanol was performed on MOF-808 to introduce more unsaturated coordination sites, thus further increasing the number of Lewis acid sites. As expected, the catalytic performance (79.1\% yield of furfuryl alcohol) of methanolactivated MOF- 808 was superior to that of pristine MOF808 [118].

\section{Conclusion and Outlook}

MOFs provide an appealing platform for constructing solid acid materials in the application of biomass upgrades. First, the inherent metal centers among MOFs can exhibit certain
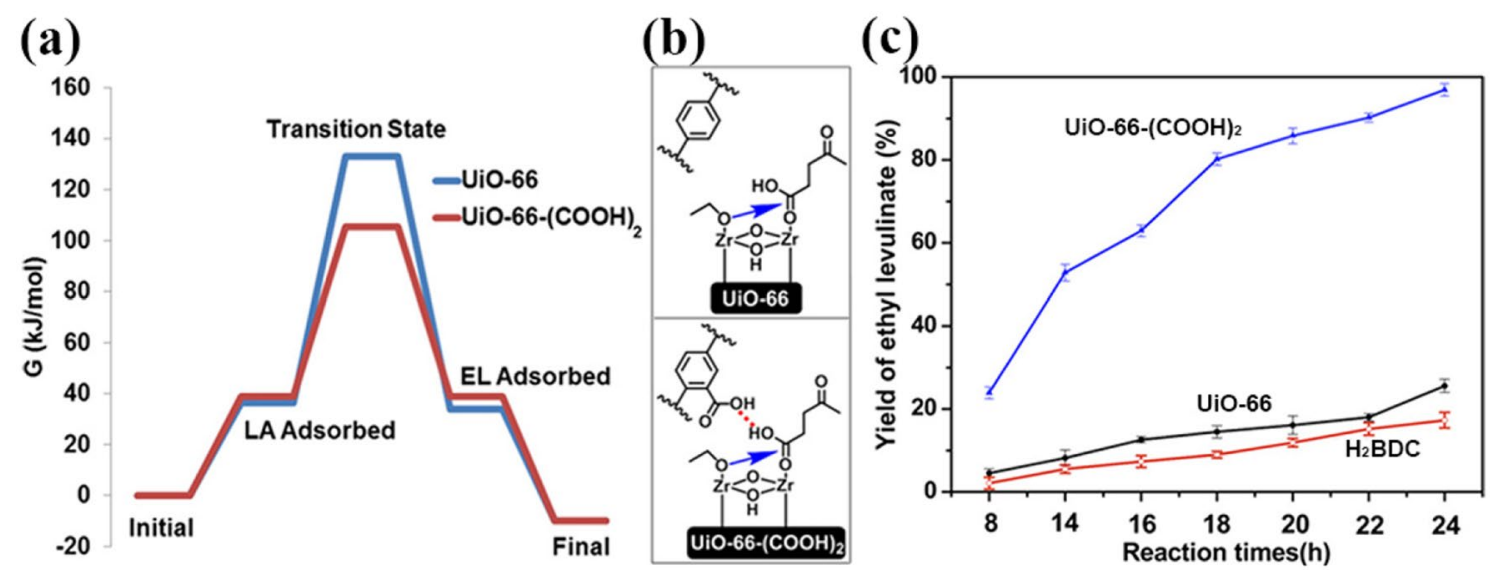

Fig. 9 a Reaction free energy profile, b proposed catalytic mechanism, and c catalytic performance of UiO-66 and UiO-66-(COOH $)_{2}$ in levulinic acid esterification. Reproduced with permission from Ref. [62]. Copyright 2019, American Chemical Society 
Lewis and Brønsted acidities, which can be further tuned by multiple strategies, such as adjusting the defective degree of the framework, altering the coordination surroundings of metal atoms, or modifying the adjacent organic linkers. Second, the organic linkers of MOFs are easily decorated by acidic functional groups, including sulfonic acid and carboxylic acid groups. Third, MOFs offer suitable rooms for the accommodation of other acidic moieties, for example, polyoxometalates and acidic metal oxides.

In comparison with conventional solid acids like zeolites and acidic polymers, MOF-based materials possess large surface areas and tunable pore structures. Therefore, they are expected to be excellent candidates for heterogeneous acid catalysts, particularly in the transformation of biomass. For example, in the conversion and utilization of saccharides, Brønsted acid can efficiently promote the hydrolysis of cellulose and oligosaccharides, while Lewis acid can catalyze the isomerization of several monosaccharides and their derivatives. As summarized in this review, MOF-based solid acids can be applied in these processes with good conversion rates, product selectivities, and recyclability.

Even if several MOF examples have exhibited huge potential in biomass conversion, further research is still needed. First, it is essential to have a comprehensive understanding of the reaction mechanism to guide rational and accurate development of the desired catalyst, in which in situ characterization tools and theoretical calculations are helpful. Second, the well-defined structures of MOFs allow precise incorporation of multiple kinds of acid functional sites at the molecular level; therefore, the synergistic effect between distinct acid sites can be facilely steered for further promoting catalytic performances. Third, the unique pore structures of MOFs can be subtly tuned to offer appropriate space for the formation of target products but not by-products, thereby greatly improving product selectivity. Furthermore, novel MOF materials of robust stability against a strong acid environment are demanded to be substantially developed.

Acknowledgements This work is funded by the National Natural Science Foundation of China (No. 21905195), Natural Science Foundation of Tianjin City (No. 20JCYBJC00800), and PEIYANG Young Scholars Program of Tianjin University (No. 2020XRX-0023).

Open Access This article is licensed under a Creative Commons Attribution 4.0 International License, which permits use, sharing, adaptation, distribution and reproduction in any medium or format, as long as you give appropriate credit to the original author(s) and the source, provide a link to the Creative Commons licence, and indicate if changes were made. The images or other third party material in this article are included in the article's Creative Commons licence, unless indicated otherwise in a credit line to the material. If material is not included in the article's Creative Commons licence and your intended use is not permitted by statutory regulation or exceeds the permitted use, you will need to obtain permission directly from the copyright holder. To view a copy of this licence, visit http://creativecommons.org/licenses/by/4.0/.

\section{References}

1. Mika LT, Cséfalvay E, Németh Á (2018) Catalytic conversion of carbohydrates to initial platform chemicals: chemistry and sustainability. Chem Rev 118(2):505-613

2. Prabhu P, Wan Y, Lee JM (2020) Electrochemical conversion of biomass derived products into high-value chemicals. Matter 3(4):1162-1177

3. Ling YF, Ma QL, Yu YF et al (2021) Optimization strategies for selective $\mathrm{CO}_{2}$ electroreduction to fuels. Trans Tianjin Univ 27(3): 180-200

4. Centi G (2020) Smart catalytic materials for energy transition. SmartMat 1(1):e1005

5. Dusselier M, van Wouwe P, Dewaele A et al (2013) Lactic acid as a platform chemical in the biobased economy: the role of chemocatalysis. Energy Environ Sci 6(5):1415-1442

6. Jing YX, Guo Y, Xia QN et al (2019) Catalytic production of value-added chemicals and liquid fuels from lignocellulosic biomass. Chem 5(10):2520-2546

7. Tao L, Yan TH, Li WQ et al (2018) Toward an integrated conversion of 5-hydroxymethylfurfural and ethylene for the production of renewable p-xylene. Chem 4(9):2212-2227

8. van Putten RJ, van der Waal JC, de Jong E et al (2013) Hydroxymethylfurfural, a versatile platform chemical made from renewable resources. Chem Rev 113(3):1499-1597

9. Zhong JW, Pérez-Ramírez J, Yan N (2021) Biomass valorisation over polyoxometalate-based catalysts. Green Chem 23(1):18-36

10. Fang RQ, Dhakshinamoorthy A, Li YW et al (2020) Metal organic frameworks for biomass conversion. Chem Soc Rev 49(11):3638-3687

11. Herbst A, Janiak C (2017) MOF catalysts in biomass upgrading towards value-added fine chemicals. CrystEngComm 19(29):4092-4117

12. Hosono N, Uemura T (2020) Metal-organic frameworks for macromolecular recognition and separation. Matter 3(3):652-663

13. Gao MY, Song BQ, Sensharma D et al (2021) Crystal engineering of porous coordination networks for $\mathrm{C} 3$ hydrocarbon separation. SmartMat 2(1):38-55

14. Guo J, Wan Y, Zhu YF et al (2020) Advanced photocatalysts based on metal nanoparticle/metal-organic framework composites. Nano Res. https://doi.org/10.1007/s12274-020-3182-1

15. Feng L, Wang KY, Lv XL et al (2020) Hierarchically porous metal-organic frameworks: synthetic strategies and applications. Natl Sci Rev 7(11):1743-1758

16. Zhao T, Li SH, Xiao YX et al (2021) Template-free synthesis to micro-meso-macroporous hierarchy in nanostructured MIL-101(Cr) with enhanced catalytic activity. Sci China Mater 64(1):252-258

17. Liu YL, Gao PF, Huang CZ et al (2015) Shape- and size-dependent catalysis activities of iron-terephthalic acid metal-organic frameworks. Sci China Chem 58(10):1553-1560

18. Furukawa H, Cordova KE, O'Keeffe M et al (2013) The chemistry and applications of metal-organic frameworks. Science 341(6149): 1230444

19. Liu JW, Chen LF, Cui H et al (2014) Applications of metalorganic frameworks in heterogeneous supramolecular catalysis. Chem Soc Rev 43(16):6011-6061

20. Gong W, Liu Y, Li HY et al (2020) Metal-organic frameworks as solid Brønsted acid catalysts for advanced organic transformations. Coord Chem Rev 420:213400

21. Niu Z, Bhagya Gunatilleke WDC, Sun Q et al (2018) Metalorganic framework anchored with a lewis pair as a new paradigm for catalysis. Chem 4(11):2587-2599 
22. Dai JJ, Zhang HB (2019) Recent advances in selective C-C bond coupling for ethanol upgrading over balanced Lewis acid-base catalysts. Sci China Mater 62(11):1642-1654

23. Yan JL, Jiang S, Ji SF et al (2015) Metal-organic framework MIL-53(Al): synthesis, catalytic performance for the FriedelCrafts acylation, and reaction mechanism. Sci China Chem 58(10):1544-1552

24. Dissegna S, Epp K, Heinz WR et al (2018) Defective metalorganic frameworks. Adv Mater 30(37): 1704501

25. Wang ZQ, Cohen SM (2009) Postsynthetic modification of metal-organic frameworks. Chem Soc Rev 38(5):1315-1329

26. Hall JN, Bollini P (2019) Structure, characterization, and catalytic properties of open-metal sites in metal organic frameworks. React Chem Eng 4(2):207-222

27. Qin JS, Yuan S, Lollar C et al (2018) Stable metal-organic frameworks as a host platform for catalysis and biomimetics. Chem Commun Camb Engl 54(34):4231-4249

28. Chui SSY, Lo SMF, Charmant JPH et al (1999) A chemically functionalizable nanoporous material $\left[\mathrm{Cu}_{3}(\mathrm{TMA})_{2}\left(\mathrm{H}_{2} \mathrm{O}\right)_{3}\right]_{n}$. Science 283(5405):1148-1150

29. Herbst A, Khutia A, Janiak C (2014) Brønsted instead of Lewis acidity in functionalized MIL-101Cr MOFs for efficient heterogeneous (nano-MOF) catalysis in the condensation reaction of aldehydes with alcohols. Inorg Chem 53(14):7319-7333

30. Rosi NL, Kim J, Eddaoudi M et al (2005) Rod packings and metal-organic frameworks constructed from rod-shaped secondary building units. J Am Chem Soc 127(5):1504-1518

31. Dhakshinamoorthy A, Santiago-Portillo A, Asiri AM et al (2019) Engineering UiO-66 metal organic framework for heterogeneous catalysis. ChemCatChem 11(3):899-923

32. Mondloch JE, Bury W, Fairen-Jimenez D et al (2013) Vaporphase metalation by atomic layer deposition in a metal-organic framework. J Am Chem Soc 135(28):10294-10297

33. Mautschke HH, Drache F, Senkovska I et al (2018) Catalytic properties of pristine and defect-engineered $\mathrm{Zr}-\mathrm{MOF}-808$ metal organic frameworks. Catal Sci Technol 8(14):3610-3616

34. Kim HK, Yun WS, Kim MB et al (2015) A chemical route to activation of open metal sites in the copper-based metal-organic framework materials HKUST-1 and Cu-MOF-2. J Am Chem Soc 137(31):10009-10015

35. Férey G, Serre C, Mellot-Draznieks C et al (2004) A hybrid solid with giant pores prepared by a combination of targeted chemistry, simulation, and powder diffraction. Angew Chem Int Ed Engl 43(46):6296-6301

36. Férey G, Mellot-Draznieks C, Serre C et al (2005) A chromium terephthalate-based solid with unusually large pore volumes and surface area. Science 309(5743):2040-2042

37. Si YN, Wang WJ, El-Sayed ESM et al (2020) Use of breakthrough experiment to evaluate the performance of hydrogen isotope separation for metal-organic frameworks M-MOF-74 $(\mathrm{M}=\mathrm{Co}, \mathrm{Ni}, \mathrm{Mg}, \mathrm{Zn})$. Sci China Chem 63(7):881-889

38. Dietzel PDC, Johnsen RE, Blom R et al (2008) Structural changes and coordinatively unsaturated metal atoms on dehydration of honeycomb analogous microporous metal-organic frameworks. Chem A Eur J 14(8):2389-2397

39. Mukherjee S, Manna B, Desai AV et al (2016) Harnessing Lewis acidic open metal sites of metal-organic frameworks: the foremost route to achieve highly selective benzene sorption over cyclohexane. Chem Commun (Camb) 52(53):8215-8218

40. Cavka JH, Jakobsen S, Olsbye U et al (2008) A new zirconium inorganic building brick forming metal organic frameworks with exceptional stability. J Am Chem Soc 130(42):13850-13851

41. Klet RC, Liu Y, Wang TC et al (2016) Evaluation of Brønsted acidity and proton topology in $\mathrm{Zr}$ - and Hf-based metal-organic frameworks using potentiometric acid-base titration. J Mater Chem A 4(4):1479-1485

42. Planas N, Mondloch JE, Tussupbayev S et al (2014) Defining the proton topology of the $\mathrm{Zr}_{6}$-based metal-organic framework NU-1000. J Phys Chem Lett 5(21):3716-3723

43. Feng D, Wang K, Su J et al (2015) A highly stable zeotype mesoporous zirconium metal-organic framework with ultralarge pores. Angew Chem Int Ed Engl 54(1):149-154

44. Furukawa H, Gándara F, Zhang YB et al (2014) Water adsorption in porous metal-organic frameworks and related materials. J Am Chem Soc 136(11):4369-4381

45. Moon SY, Liu Y, Hupp JT et al (2015) Instantaneous hydrolysis of nerve-agent simulants with a six-connected zirconiumbased metal-organic framework. Angew Chem Int Ed Engl 54(23):6795-6799

46. Liu YY, Klet RC, Hupp JT et al (2016) Probing the correlations between the defects in metal-organic frameworks and their catalytic activity by an epoxide ring-opening reaction. Chem Commun 52(50):7806-7809

47. Yang D, Bernales V, Islamoglu T et al (2016) Tuning the surface chemistry of metal organic framework nodes: proton topology of the metal-oxide-like $\mathrm{Zr}_{6}$ nodes of UiO-66 and NU-1000. J Am Chem Soc 138(46):15189-15196

48. Taddei M (2017) When defects turn into virtues: the curious case of zirconium-based metal-organic frameworks. Coord Chem Rev 343:1-24

49. Feng X, Hajek J, Jena HS et al (2020) Engineering a highly defective stable UiO-66 with tunable Lewis-Brønsted acidity: the role of the hemilabile linker. J Am Chem Soc 142(6):3174-3183

50. Jiang JC, Gándara F, Zhang YB et al (2014) Superacidity in sulfated metal-organic framework-808. J Am Chem Soc 136(37):12844-12847

51. Ji PF, Feng X, Oliveres P et al (2019) Strongly lewis acidic metal-organic frameworks for continuous flow catalysis. J Am Chem Soc 141(37):14878-14888

52. Trickett CA, Osborn Popp TM, Su J et al (2019) Identification of the strong Brønsted acid site in a metal-organic framework solid acid catalyst. Nat Chem 11(2):170-176

53. Wu H, Chua YS, Krungleviciute V et al (2013) Unusual and highly tunable missing-linker defects in zirconium metal-organic framework UiO-66 and their important effects on gas adsorption. J Am Chem Soc 135(28):10525-10532

54. Xu ZM, Cao JZ, Chen X et al (2021) Enhancing photocatalytic performance of $\mathrm{NH}_{2}$-UIO66 by defective structural engineering. Trans Tianjin Univ 27(2):147-154

55. Vermoortele F, Bueken B, Le Bars G et al (2013) Synthesis modulation as a tool to increase the catalytic activity of metalorganic frameworks: the unique case of UiO-66(Zr). J Am Chem Soc 135(31):11465-11468

56. Song Y, Feng X, Chen JS et al (2020) Multistep engineering of synergistic catalysts in a metal-organic framework for tandem C-O bond cleavage. J Am Chem Soc 142(10):4872-4882

57. Guillerm V, Xu H, Albalad J et al (2018) Postsynthetic selective ligand cleavage by solid-gas phase ozonolysis fuses micropores into mesopores in metal-organic frameworks. J Am Chem Soc 140(44):15022-15030

58. Ji P, Drake T, Murakami A et al (2018) Tuning Lewis acidity of metal-organic frameworks via perfluorination of bridging ligands: spectroscopic, theoretical, and catalytic studies. J Am Chem Soc 140(33):10553-10561

59. Timofeeva MN, Panchenko VN, Jun JW et al (2014) Effects of linker substitution on catalytic properties of porous zirconium terephthalate UiO-66 in acetalization of benzaldehyde with methanol. Appl Catal A Gen 471:91-97 
60. Vermoortele F, Vandichel M, van de Voorde B et al (2012) Electronic effects of linker substitution on Lewis acid catalysis with metal-organic frameworks. Angew Chem Int Ed Engl 51(20):4887-4890

61. Zhang Z, Liu YW, Tian HR et al (2020) Polyoxometalate-based metal-organic framework fractal crystals. Matter 2(1):250-260

62. Wang FF, Chen ZJ, Chen HY et al (2019) Interplay of Lewis and Brønsted acid sites in Zr-based metal-organic frameworks for efficient esterification of biomass-derived levulinic acid. ACS Appl Mater Interfaces 11(35):32090-32096

63. Ragon F, Campo B, Yang QY et al (2015) Acid-functionalized UiO-66(Zr) MOFs and their evolution after intra-framework cross-linking: structural features and sorption properties. J Mater Chem A 3(7):3294-3309

64. Tian YM, Liang G, Fan T et al (2019) Grafting free carboxylic acid groups onto the pore surface of 3D porous coordination polymers for high proton conductivity. Chem Mater 31(20):8494-8503

65. Biswas S, Zhang J, Li ZB et al (2013) Enhanced selectivity of $\mathrm{CO}_{2}$ over $\mathrm{CH}_{4}$ in sulphonate-, carboxylate- and iodo-functionalized UiO-66 frameworks. Dalton Trans 42(13):4730-4737

66. Lin Foo M, Horike S, Fukushima T et al (2012) Ligand-based solid solution approach to stabilisation of sulphonic acid groups in porous coordination polymer $\mathrm{Zr}_{6} \mathrm{O}_{4}(\mathrm{OH})_{4}(\mathrm{BDC})_{6}(\mathrm{UiO}-66)$. Dalton Trans 41(45):13791-13794

67. Hu Z, Peng Y, Gao Y et al (2016) Direct synthesis of hierarchically porous metal-organic frameworks with high stability and strong Brønsted acidity: the decisive role of hafnium in efficient and selective fructose dehydration. Chem Mater 28(8):2659-2667

68. Akiyama G, Matsuda R, Sato H et al (2011) Cellulose hydrolysis by a new porous coordination polymer decorated with sulfonic acid functional groups. Adv Mater 23(29):3294-3297

69. Ma DX, Li BY, Shi Z (2018) Multi-functional sites catalysts based on post-synthetic modification of metal-organic frameworks. Chin Chem Lett 29(6):827-830

70. Tanabe KK, Cohen SM (2011) Postsynthetic modification of metal-organic frameworks: a progress report. Chem Soc Rev 40(2):498-519

71. Gadzikwa T, Farha OK, Mulfort KL et al (2009) A Zn-based, pillared paddlewheel MOF containing free carboxylic acids via covalent post-synthesis elaboration. Chem Commun 25:3720-3722

72. Garibay SJ, Wang Z, Cohen SM (2010) Evaluation of heterogeneous metal-organic framework organocatalysts prepared by postsynthetic modification. Inorg Chem 49(17):8086-8091

73. Williams K, Meng L, Lee S et al (2016) Imparting Brønsted acidity into a zeolitic imidazole framework. Inorg Chem Front 3(3):393-396

74. Chen JZ, Li KG, Chen LM et al (2014) Conversion of fructose into 5-hydroxymethylfurfural catalyzed by recyclable sulfonic acid-functionalized metal-organic frameworks. Green Chem 16(5):2490-2499

75. Li BY, Zhang YM, Ma DX et al (2012) A strategy toward constructing a bifunctionalized MOF catalyst: post-synthetic modification of MOFs on organic ligands and coordinatively unsaturated metal sites. Chem Commun 48(49):6151-6153

76. Britt D, Lee C, Uribe-Romo FJ et al (2010) Ring-opening reactions within porous metal-organic frameworks. Inorg Chem 49(14):6387-6389

77. Phang WJ, Jo H, Lee WR et al (2015) Superprotonic conductivity of a UiO-66 framework functionalized with sulfonic acid groups by facile postsynthetic oxidation. Angew Chem Int Ed 54(17):5142-5146
78. Feng L, Wang KY, Powell J et al (2019) Controllable synthesis of metal-organic frameworks and their hierarchical assemblies. Matter 1(4):801-824

79. Dhakshinamoorthy A, Garcia H (2012) Catalysis by metal nanoparticles embedded on metal-organic frameworks. Chem Soc Rev 41(15):5262-5284

80. Buru CT, Farha OK (2020) Strategies for incorporating catalytically active polyoxometalates in metal-organic frameworks for organic transformations. ACS Appl Mater Interfaces 12(5):5345-5360

81. Chen LY, Xu Q (2019) Metal-organic framework composites for catalysis. Matter 1(1):57-89

82. Yang L, Naruke H, Yamase T (2003) A novel organic/inorganic hybrid nanoporous material incorporating Keggin-type polyoxometalates. Inorg Chem Commun 6(8):1020-1024

83. Sun CY, Liu SX, Liang DD et al (2009) Highly stable crystalline catalysts based on a microporous metal-organic framework and polyoxometalates. J Am Chem Soc 131(5):1883-1888

84. Ahn S, Nauert SL, Buru CT et al (2018) Pushing the limits on metal-organic frameworks as a catalyst support: NU-1000 supported tungsten catalysts for o-xylene isomerization and disproportionation. J Am Chem Soc 140(27):8535-8543

85. Paille G, Gomez-Mingot M, Roch-Marchal C et al (2018) A fully noble metal-free photosystem based on cobalt-polyoxometalates immobilized in a porphyrinic metal-organic framework for water oxidation. J Am Chem Soc 140(10):3613-3618

86. Swift TD, Bagia C, Choudhary V et al (2014) Kinetics of homogeneous Brønsted acid catalyzed fructose dehydration and 5-hydroxymethyl furfural rehydration: a combined experimental and computational study. ACS Catal 4(1):259-267

87. Choudhary V, Mushrif SH, Ho C et al (2013) Insights into the interplay of Lewis and Brønsted acid catalysts in glucose and fructose conversion to 5-(hydroxymethyl)furfural and levulinic acid in aqueous media. J Am Chem Soc 135(10):3997-4006

88. Corma A, Iborra S, Velty A (2007) Chemical routes for the transformation of biomass into chemicals. Chem Rev 107(6):2411-2502

89. Yang XK, Li T, Tang K et al (2017) Highly efficient conversion of terpenoid biomass to jet-fuel range cycloalkanes in a biphasic tandem catalytic process. Green Chem 19(15):3566-3573

90. Voß D, Pickel H, Albert J (2019) Improving the fractionated catalytic oxidation of lignocellulosic biomass to formic acid and cellulose by using design of experiments. ACS Sustain Chem Eng 7(11):9754-9762

91. Wang KF, Liu Y, Wu WF et al (2020) Production of levulinic acid via cellulose conversion over metal oxide-loaded MOF catalysts in aqueous medium. Catal Lett 150(2):322-331

92. Akiyama G, Matsuda R, Sato H et al (2014) Catalytic glucose isomerization by porous coordination polymers with open metal sites. Chem Asian J 9(10):2772-2777

93. Luo QX, Zhang YB, Qi L et al (2019) Glucose isomerization and epimerization over metal-organic frameworks with singlesite active centers. ChemCatChem 11(7):1903-1909

94. Rojas-Buzo S, Corma A, Boronat M et al (2020) Unraveling the reaction mechanism and active sites of metal-organic frameworks for glucose transformations in water: experimental and theoretical studies. ACS Sustain Chem Eng 8(43):16143-16155

95. Liu LM, Chen ZJ, Wang JJ et al (2019) Imaging defects and their evolution in a metal-organic framework at sub-unit-cell resolution. Nat Chem 11(7):622-628

96. Chang X, Zhang CY, Gao L et al (2019) Tandem biocatalysis by CotA-TJ102@UIO-66- $\mathrm{NH}_{2}$ and novozym 435 for highly selective transformation of HMF into FDCA. Trans Tianjin Univ 25(5):488-496 
97. Wang HL, Song Y, Liu X et al (2020) Preparation of anisotropic $\mathrm{MnO}_{2}$ nanocatalysts for selective oxidation of benzyl alcohol and 5-hydroxymethylfurfural. Trans Tianjin Univ 26(5):382-390

98. Zhang Y, Degirmenci V, Li C et al (2011) Phosphotungstic acid encapsulated in metal-organic framework as catalysts for carbohydrate dehydration to 5-hydroxymethylfurfural. Chemsuschem 4(1):59-64

99. Su Y, Chang GG, Zhang ZG et al (2016) Catalytic dehydration of glucose to 5-hydroxymethylfurfural with a bifunctional metalorganic framework. AIChE J 62(12):4403-4417

100. Yabushita M, Li P, Islamoglu T et al (2017) Selective metalorganic framework catalysis of glucose to 5-hydroxymethylfurfural using phosphate-modified NU-1000. Ind Eng Chem Res 56(25):7141-7148

101. Pagis C, Ferbinteanu M, Rothenberg G et al (2016) Lanthanidebased metal organic frameworks: synthetic strategies and catalytic applications. ACS Catal 6(9):6063-6072

102. Burnett DL, Oozeerally R, Pertiwi R et al (2019) A hydrothermally stable ytterbium metal-organic framework as a bifunctional solid-acid catalyst for glucose conversion. Chem Commun 55(76):11446-11449

103. Qu HN, Liu BY, Gao GH et al (2019) Metal-organic framework containing Brønsted acidity and Lewis acidity for efficient conversion glucose to levulinic acid. Fuel Process Technol 193:1-6

104. Dusselier M, Sels BF (2014) Selective catalysis for cellulose conversion to lactic acid and other $\alpha$-hydroxy acids. In: BoucherJacobs C, Bozell JJ, Chen EY et al (eds) Selective catalysis for renewable feedstocks and chemicals. Springer, Berlin, pp 98-108

105. Lu XL, Wang LX, Lu XY (2018) Catalytic conversion of sugars to methyl lactate over Mg-MOF-74 in near-critical methanol solutions. Catal Commun 110:23-27

106. Murillo B, Zornoza B, de la Iglesia O et al (2016) Chemocatalysis of sugars to produce lactic acid derivatives on zeolitic imidazolate frameworks. J Catal 334:60-67

107. Murillo B, Zornoza B, de la Iglesia O et al (2019) (2019) Tincarboxylate MOFs for sugar transformation into methyl lactate. Eur J Inorg Chem 21:2624-2629

108. Choudhary V, Sandler SI, Vlachos DG (2012) Conversion of xylose to furfural using Lewis and Brønsted acid catalysts in aqueous media. ACS Catal 2(9):2022-2028

109. Nakagawa Y, Yabushita M, Tomishige K (2021) Reductive conversion of biomass-derived furancarboxylic acids with retention of carboxylic acid moiety. Trans Tianjin Univ 27(3):165-179

110. Liu Y, Ma CJ, Huang CX et al (2018) Efficient conversion of xylose into furfural using sulfonic acid-functionalized metalorganic frameworks in a biphasic system. Ind Eng Chem Res 57(49):16628-16634

111. Chatterjee A, Hu XJ, Lam FL-Y (2018) A dual acidic hydrothermally stable MOF-composite for upgrading xylose to furfural. Appl Catal A: Gen 566:130-139

112. Cirujano FG, Corma A, Llabrési Xamena FX (2015) Conversion of levulinic acid into chemicals: synthesis of biomass derived levulinate esters over Zr-containing MOFs. Chem Eng Sci 124:52-60

113. Caratelli C, Hajek J, Cirujano FG et al (2017) Nature of active sites on UiO-66 and beneficial influence of water in the catalysis of Fischer esterification. J Catal 352:401-414
114. Wang ZH, Chen QW (2016) Conversion of 5-hydroxymethylfurfural into 5-ethoxymethylfurfural and ethyl levulinate catalyzed by MOF-based heteropolyacid materials. Green Chem 18(21):5884-5889

115. Lin Q, Li YH, Tang ZR et al (2020) Valorization of biomassderived platform molecules via photoredox sustainable catalysis. Trans Tianjin Univ 26(5):325-340

116. Zhao M, Yuan K, Wang Y et al (2016) Metal-organic frameworks as selectivity regulators for hydrogenation reactions. Nature 539(7627):76-80

117. Assary RS, Curtiss LA, Dumesic JA (2013) Exploring meerweinponndorf-verley reduction chemistry for biomass catalysis using a first-principles approach. ACS Catal 3(12):2694-2704

118. Valekar AH, Lee M, Yoon JW et al (2020) Catalytic transfer hydrogenation of furfural to furfuryl alcohol under mild conditions over Zr-MOFs: exploring the role of metal node coordination and modification. ACS Catal 10(6):3720-3732

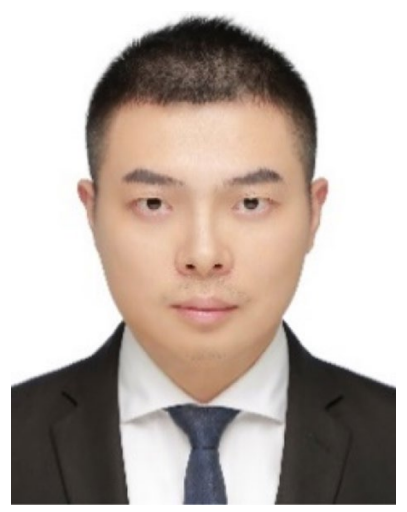

Jun Guo received his B.S. degree from Huazhong University of Science and Technology in 2012. Then, he obtained his Ph.D. degree from Peking University and National Center for Nanoscience and Technology in 2018 under the guidance of Prof. Zhiyong Tang and Prof. Hailin Peng. In 2021, after finishing his postdoctoral career in Prof. Hua Zhang's group in City University of Hong Kong, he joined Tiangong University as a professor. Currently, his research interests mainly focus on the synthesis of multifunctional porous nanomaterials for application in catalysis, separation and biomedicine.

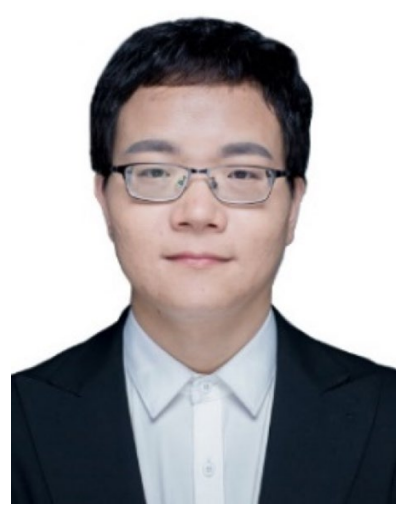

Meiting Zhao obtained his Ph.D. degree from National Center for Nanoscience and Technology in 2014 under the guidance of Prof. Zhiyong Tang. Then he worked as a postdoctoral research fellow in Prof. Hua Zhang's group in Nanyang Technological University. In 2019, he joined Tianjin University as a professor. His research interests include the structure design, controlled synthesis and application of MOFs in selective catalysis, separation and energy conversion. 